NASA Technical Memorandum 103994

\title{
Assessment of Nonequilibrium Radiation Computation Methods for Hypersonic Flows
}

\section{Surendra Sharma}

January 1993

Quick Release - This Technical Memorandum is an unedited report. It is being released in this format to quickly provide the research community with important information.

(NASA-TM-103994) ASSESSMENT OF

N93-19348 NONEQUILIBRIUM RADIATION COMPUTATION METHODS FOR HYPERSONIC FLOWS (NASA) $41 \mathrm{p}$

Unclas

$63 / 34 \quad 0146058$

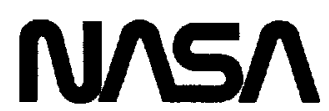

National Aeronautics and Space Administration 
NASA Technical Memorandum 103994

\section{Assessment of Nonequilibrium Radiation Computation Methods for Hypersonic Flows}

Surendra Sharma, Ames Research Center, Moffett Field, California

January 1993

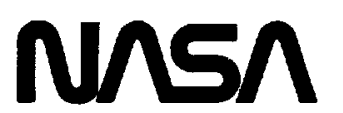

National Aeronautics and

Space Administration 



\section{SUMMARY}

The present understanding of shock-layer radiation in the low density regime, as appropriate to hypersonic vehicles, is surveyed. Based on the relative importance of electron excitation and radiation transport, the hypersonic flows are divided into three groups: weakly ionized, moderately ionized, and highly ionized flows. In the light of this division, the existing laboratory and flight data are scrutinized. Finally, an assessment of the nonequilibrium radiation computation methods for the three regimes in hypersonic flows is presented. The assessment is conducted by comparing experimental data against the values predicted by the physical model.

\section{NOMENCLATURE}

\begin{tabular}{|c|c|}
\hline$A_{i, j}$ & Einstein transition probability for spontancous cmission \\
\hline$B_{\lambda}$ & Planck function \\
\hline$c$ & velocity of light, $\mathrm{cm} / \mathrm{sec}$ \\
\hline$<c>$ & average thermal speed, $\mathrm{cm} / \mathrm{sec}$ \\
\hline$C$ & constant, equation 2 \\
\hline$e_{v}$ & average vibrational energy per unit mass, $J / k g$ \\
\hline$e_{v E}$ & average vibrational energy per unit mass at equilibrium, $J / \mathrm{kg}$ \\
\hline$e_{R}$ & average rotational energy per unit mass, $J / k g$ \\
\hline$e_{R E}$ & avcragc rotational cnergy per unit mass at equilibrium, $\mathrm{J} / \mathrm{kg}$ \\
\hline$h$ & Planck constant \\
\hline$k$ & Boltzmann constant \\
\hline$K$ & rate constant, $\mathrm{cm}^{3} / \mathrm{sec}$ \\
\hline$\kappa$ & absorption coefficient, $\mathrm{cm}^{-1}$ \\
\hline$n$ & constant, cquation 2 \\
\hline$N$ & number density, $\mathrm{cm}^{-3}$ \\
\hline$p$ & pressure, atmosphere \\
\hline$T$ & translational temperature, $\mathrm{K}$ \\
\hline$T_{a}$ & geometrical mean temperature, $\mathrm{K}$ \\
\hline$T_{d}$ & characteristic temperaturc of dissociation, $\mathrm{K}$ \\
\hline$T_{e}$ & electron temperature, $\mathrm{K}$ \\
\hline$T_{e x}$ & excitation temperature (eq. 1), K \\
\hline$T_{R}$ & rotational temperature, $\mathrm{K}$ \\
\hline$T_{v}$ & vibrational temperature, $\mathrm{K}$ \\
\hline$v$ & vibrational quantum number \\
\hline$\tau_{L}$ & relaxation time deduced from the Landau-Teller equation, sec \\
\hline
\end{tabular}




\section{INTRODUCTION}

The physics of the compressed gas layer behind a shock wave surrounding a hypersonic object flying through a planetary atmosphere have been studied intensely since the early 1960's (refs. 1-18).. The intense heat generated as a result of the compression is distributed in the shock layer volume through a thermochemical relaxation process. The translational temperature immediately behind the shock may be as high as 20,000 to $60,000 \mathrm{~K}$. Due to the high velocity of the vehicle the characteristic flow time through the shock layer becomes comparable to the relaxation time constants of these thermochemical processes and, as a result, a major volume of the shock layer is in a state of thermochemical nonequilibrium. The radiation from the volume in thermochemical nonequilibrium is enhanced, about 2-15 times higher than its equilibrium value (ref. 16). In such an environment, the nonequilibrium radiation plays a larger role in the radiative heating of the vehicle body. In order to properly design the heat shiclds of such vehicles one must be able to compute the radiative and convective heat load. The convective heat transfer rates can be estimated with confidence provided the surface catalytic reactivity is known (ref. 19). The nonequilibrium radiation phenomena is still not well understood, especially, at high altitudes $(>50 \mathrm{~km})$ and at velocities above $10.0 \mathrm{~km} / \mathrm{sec}$ and bclow $6.0 \mathrm{~km} / \mathrm{scc}$.

There are three basic features which are unique to nonequilibrium radiation:

1. For a given transition, the absorption coefficient, $\kappa$, and the emission coefficient, $\epsilon$ must satisfy the principle of detailed balance unique to that particular transition, independently of all other transitions occurring concurrently

$$
\epsilon=\kappa B_{\lambda}\left(T_{e x}\right), \quad B_{\lambda}\left(T_{e x}\right)=\frac{8 \lambda h c}{\lambda^{5}} \frac{\exp \left(-h c / \lambda k T_{e x}\right)}{1-\exp \left(-h c / \lambda k T_{e x}\right)}
$$

where $B_{\lambda}\left(T_{e x}\right)$ is the Planck function dictated by the excitation temperature for a particular transition. This condition is satisfied, whether the gas is in radiative equilibrium or not. If radiative equilibrium exits, the total absorption coefficient, $\kappa_{t}=\sum \kappa$ and the total emission coefficient, $\epsilon_{t}=\sum \epsilon$ are also related by the same excitation temperature. In noncquilibrium radiation a single excitation temperature docs not exist.

2. During the relaxation process a state of chemical nonequilibrium exits. The populations of individual radiating species are functions of time (or distance), and must be determined by solving a set of chemical reaction rate equations simultancously with the thermodynamic and gasdynamic cquations.

3. The internal energy distribution for the molecules as well as the atoms can not be uniquely defined. The molecular populations in individual rotational states is defined by a rotational temperaturc, $T_{R}$. The distribution electron encrgy is defined by an electron temperature, $T_{c}$. The populations in atomic and molecular electronic levels can not be defined by a single temperature. Instead, they are determined by solving another set of 
rate equations under the so-called quasi-steady-state (QSS) approximation (ref. 7). Recent computations (ref. 20) suggest that the vibrational populations of the molecules can not be determined by assuming a single vibrational temperature, $T_{v}$ and, in principle at least, should be determined by solving a set of master equations (rcf. 20). Even in the simplest models, one must define a vibrational temperature for the vibrational degree of freedom of the molecules. Also individual molecular species may not have the same vibrational tempcrature (ref. 21).

During the Apollo era to understand the basic physics of nonequilibrium radiation and compute the radiative load to the vehicle, the radiative phenomena were studied extensively through laboratory (refs. 1-3) and flight tests (refs. 10-14). In a concerted effort in the laboratory, shock tube and ballistic range tests were conducted along with theoretical calculations. Shock tubes were opcrated (refs. 1-3) at shock velocities up to $10 \mathrm{~km} / \mathrm{sec}$. There was a lower limit on the gas density in these tests because of intrinsic limitations of a shock tube, such as boundary layer growth and short test times. At the shock velocity of $7 \mathrm{~km} / \mathrm{sec}$, the lowest initial pressure ahead of the shock wave was 0.05 Torr $(\sim 70 \mathrm{~km}$ altitude). At the shock velocity of $10 \mathrm{~km} / \mathrm{scc}$, the lowest pressure was 0.1 Torr ( $65 \mathrm{~km}$ altitude). One of the major findings of the laboratory data was that the luminosity of air is zero immediately behind the shock, rises to a peak, then, decays to a smaller value and achieves a plateau (fig. 1). This plateau suggests the onset of a steady state (very close to equilibrium). This nonequilibrium radiation ovcrshoot was interpreted as being duc to the thermochemical nonequilibrium. The molecules with high binding energy $(\sim 9.8 \mathrm{cV})$ require a long time to dissociate, as the molecule cascaded towards the dissociation limit by way of collisional energy transfers. Before it could dissociate to its equilibrium value, the temperature rose to a higher level than its equilibrium value, causing the luminosity overshoot. However, the first attempts to theoretically simulate the radiation overshoot were unsuccessful. The model should allow the reaction rates to be small at the initial stage of the relaxation process and, then, to grow exponentially near the final stages of the process. If one uses the conventional formulation for reaction rate, $\mathrm{K}$,

$$
\text { Reaction rate, } K=C T^{n} \exp \left(-T_{d} / T\right)
$$

with the translational temperature as the controlling temperature, then the maximum radiation occurs immediately behind the shock, where the temperature is maximum. Attempts to attribute the incubation period to the noncquilibrium vibrational excitation have also failed, because peak in radiation occurs much later in time than predicted by the vibrational relaxation theory using Landau-Teller formulation (ref. 22). Over the years several investigators (refs. 23-28) have suggested that the dissociation and vibrational relaxation processes be coupled together in order to explain this long incubation period to the peak radiation.

Recently, Park (rcf. 29), was able to thcoretically simulate the slow relaxation and radiation overshoot for shock velocities in the range of $6-10 \mathrm{~km} / \mathrm{sec}$ using a multi-temperature model $\left(T_{v}=T_{e} \neq T_{R}=T\right)$, by suggesting that an average temperature, $T_{a}=\sqrt{T T_{v}}$ controls the rcaction rates in cquation (2). The model also suggests that at very high temperatures the vibrational relaxation changes its character from Landau-Teller type to a slower diffusion typc (ref. 29). 
Since chemical and thermodynamic processes in the relaxation zone are binary, i.e. they result from two body collisions, the intensity of radiation from such reactions is proportional to the density and the thickness of the relaxation zone is inversely proportional to the density. Consequently, as long as the binary mechanism dominates, the integrated radiation flux emitted from such a nonequilibrium region remains independent of density at a given velocity (refs. 2 and 3). This property is called the "binary scaling" law of nonequilibrium radiation. There are four mechanisms which may depress, either the nonequilibrium or equilibrium radiative load to a body, and thus violate the binary scaling law: 1) Truncation occurs (ref. 2) when the width of the nonequilibrium region is thicker than the shock detachment distance, 2) collisional limiting (ref. 8) reduces the radiation intensity at low densities when the collisions to maintain the population of excited states against the depletion by emission are not sufficient, 3) radiation cooling occurs when energy loss by radiation is significant, and 4) the gas is not always optically thin and reabsorption in the gas may occur.

Electrons play a dominant role in the excitation and emission process. Electrons are about a million times more efficient than neutral particles and few hundred times than ions in causing electronic excitations of atoms and molecules by collisions. Furthermore, experiments show (ref. 30) that high clectronic states, which primarily contribute to the emission, remain in equilibrium with the electrons described by a local Saha equation. Thus, for singly ionized species $\left(N_{e} \sim N_{\text {ions }}\right)$, the population of excited electronic states is maintained proportional to the square of the electron number density. In this case

$$
\text { Spontaneous radiative power }=h \nu A_{i, j} N_{i} g_{i} \sim h \nu A_{i, j} N_{e}^{2}
$$

where $A_{i, j}$ is the Einstcin transition probability for spontaneous emission for the $i \rightarrow j$ transition, $N_{i}$ is the number density of the ith electronic level and $g_{i}$ is the degeneracy of the ith level. The electrons not only affect the line radiation but also the continuum radiation as well. The continuum radiation, either due to free-free transition $\left(\propto N_{e}^{2}\right)$ or due to bound-free recombination process $\left(\propto N_{e}\right)$ or due to density packed bound-bound line radiations $\left(\propto N_{e}^{2}\right)$, can add up to a significant portion of the total radiative power, especially in an optically thick cnvironment.

Thus it is seen that the nonequilibrium radiation is affected not only by the thermochemical nonequilibrium in the media, but also by the vehicle size and flight altitude. Also, to a certain degree, the nature of radiation depends upon the electron density. Todate, various radiation models have been reported in the literature, each of which capture some of the important features of nonequilibrium radiation. This survey paper examines the capabilities of these models and summarizes the status of our present day understanding of the physics of noncquilibrium radiation. As an example, the results obtained from the computer program named NonEquilibrium AIr Radiation (NEQAIR) written by Park (ref. 7) at NASA Ames Rescarch Center, Moffett Field, California, U.S.A., will be referred most frequently. The available experimental data, from laboratories as well from flight experiments is surveyed. Finally some of the results obtained using these models are discussed and compared with the experimental data. The nonequilibrium radiation as a whole is divided into three groups: 
(i) Radiation at low ionization, $N_{e} / N<0.01 \%$.

(ii) Radiation at moderatc ionization, $3 \%>N_{e} / N>0.01 \%$.

(iii) Radiation at high degrec of ionization, $N_{e} / N>3 \%$.

\section{PHYSICS OF NONEQUILIBRIUM RADIATION}

\section{A. Atomic Radiation}

In order to calculate the total radiation from a bound-bound optical transition $(i \rightarrow j)$ one must compute the spontancous radiation $\left(\propto N_{i}\right)$, the stimulated radiation $\left(\propto N_{i}\right)$, and the absorbed radiation $\left(\propto N_{j}\right.$ ). This requires the knowledge of number densities, $N_{i}$ and $N_{j}$. As mentioned before $N_{i}$ and $N_{j}$ are related by a local excitation temperature (eq. (1)). Under nonequilibrium conditions the number density of any given state, ' $i$ ' of an atom or molecule changes with time and is a sum of the diffusion rate and the net chemical production rate. The chemical processes consist of collisional and radiative transitions. For internal states, however, the chemical production as well as chemical removal rates are usually much larger than the diffusion term. This leads to the QSS approximation

$$
\begin{aligned}
\frac{\partial N_{i}}{\partial t}= & \overbrace{\sum_{j=1}^{\infty} K(j, i) N_{j} N_{e}+K(c, i) N_{+} N_{e}^{2}}^{\text {collisional }}+\overbrace{\sum_{j=1}^{\infty} A_{j, i} N_{j}+A_{c, i} N_{+} N_{c}}^{\text {radiative }} \\
& -\overbrace{\sum_{j=1}^{\infty} K(i, j) N_{i} N_{e}-K(i, c) N_{i} N_{e}}^{\text {collisional }}-\overbrace{\sum_{j=1}^{\infty} A_{i, j} N_{i}-A_{i, c} N_{i}}^{\text {removal }} \\
& \approx 0 \quad\left(i f \frac{10^{6}}{N_{e}} \ll \partial t, Q S S\right)
\end{aligned}
$$

here $N_{e}$ is the clectron number density (the colliding particle). $K(i, j)$ is the rate coefficient for $i \rightarrow j$ electronic transition, and $K(i, c)$ and $K(c, i)$ are the rate coefficients for $i \rightarrow$ free and free $\rightarrow i$ transitions, respectively. The rate coefficients are obtained by the integration of corresponding cross sections over collision energy from the threshold value to infinity. In gencral the colliding particles can be a heavy particle and an electron. However, since the electrons are several orders of magnitudes more effective in causing electronic or vibrational transitions than heavy particles, for these transitions the contributions of heavy particles may be neglected (ref. 32). Detcrmining the number densitics, $\mathrm{N}_{i}$, by solving the QSS Equations (cq. (4)), in essence, wc assumc a multi electronic tempcrature model for each species while computing the radiative emission (and/or absorption). 
In general, of the three atomic radiative processes, namely: 1) line radiation, 2) free-bound radiation, and 3) free-free radiation, the radiative intensity from the first two are affected by tine populations of all internal electronic states. The free-free radiation is not affected by the internal state populations. For the computation of the line atomic radiation and free-bound continuum the populations of all electronic states are determined by solving a set of equations like equation (4). The transitions that need to be considered in eq. (4), can be divided into four groups:

1. Transitions among high states $(i \geq 4)$. A QSS condition is assumed to exist among these states. The rate coefficients for the radiative transitions can be calculated by using references 33 and 34 . The collisional rate coefficients are derived by Bates (ref. 35) using the semi-classical theory of Gryzinsky (refs. 36 and 37) for a hydrogen force field. The collisional rates of Bates can be used for $\mathrm{N}$ and $\mathrm{O}$ with an effective quantum number i.e. replacing $E_{H} / n^{2}$ by $\left(E_{\infty}-E(i)\right)$. Here $E_{H}$ is the ionization potential for hydrogen and $n$ its principle quantum number.

2. Transition among low lying states $(i \leq 3)$. A QSS state does not exist among these states. However, they maintain a state of equilibrium among themselves and their populations can be described by a Boltzmann distribution. In order to compensate for the large departure from a hydrogenic structure for the three low lying states in atoms such as nitrogen, a correction factor can be used (sce ref. 38). Within the framework of Gryzinski's theory this correction factor applies only to the initial states and is independent of the final state. However, at low densities and highly nonequilibrium regimes the correction factor for a singlet-to-singlet transitions may be different than for a singlet-to-multilet transition. Thus the applicability of Gryzinski's theory to the low density high velocity regimes needs to be further researched.

3. Transitions from the ground state to the high excited state. Experimental data for collisional excitation are available (refs. 38-40).

4. Transitions from the low lying states $(i \leq 3)$ to the high states. Due to lack of additional data the cross section for this transition can be assumed to be the same as for the transition from ground to the high excited states.

In a collision dominated plasma, when the contribution of radiative transition to equation (4) is not significant, the population distribution of the electronic states becomes independent of electron number density and insensitive to the excitation rate coefficients, or to errors in their estimates. A collision-dominant condition exits in one of the following situations:

a. Optically thick gas.

b. Optically thin gas with sufficiently high number of electrons.

$$
K(i, j) \gg \frac{A_{i, j}}{N_{r}}, i>j \text { and } i, j \geq 4
$$


For nitrogen this conditions is satisfied for $\mathrm{N}_{e}>10^{18} \mathrm{~cm}^{-3}$.

c. Partially optically thick gas. For a given optical depth there exists an upper limit for the electron number density $\left(<10^{18} \mathrm{~cm}^{-3}\right)$ when a partially thick gas becomes collisionally dominated. For cxample at $\mathrm{T}=12000 \mathrm{~K}$ in nitrogen this limit is $N_{c} \geq$ $10^{16} \mathrm{~cm}^{-3}$. If the far ultraviolet radiation is cut off, then the limit for nitrogen is $N_{e} \geq 10^{14} \mathrm{~cm}^{-3}$.

Of course at electron densities below the limiting value, the radiative transitions must also be included in the calculations.

The integrated intensity from spontancous emission is distributed over a spectral line shapc. Most realistic line shape can be approximated by the Voigt line shape (ref. 41), which combines the Lorentzian and Gaussian line shapes into one. The Gaussian shape is produced by the thermal motion of atoms. Overall line shape, however, is due to combined effects of natural broadening, Stark broadening (electron collisions), Van der Waals broadening (other species collisions) and resonance broadening (same species collisions). At low densities of present interest, the line shapes can be assumed to be symmetrical about the centerline (ref. 41) and unshifted by collisions. However, in certain cases, asymmetric line profiles due to Van der Waals broadening may occur (ref. 42).

When the clectron number density is in excess of $3 \%(\geq 9.0 \mathrm{~km} / \mathrm{sec})$ Kramers' radiation, namely: free-frec, produced by deceleration of an electron in the clectric field of an ion or atom, and free-bound, produced by capture of an electron by an ion, also becomes important.

\section{B. Molecular Radiation}

The molecular spectra for any given clectronic transition consists of a vibrational band system with a rotational structure. In order to compute the radiation from each of the rotational lines one must detcrmine the rotational populations in cach of the involved vibrational and electronic states. The excitation energies of molecular rotation are usually very small. For example, the temperature equivalent for oxygen is $2.1 \mathrm{~K}$ and for nitrogen is $2.9 \mathrm{~K}$. Therefore, at temperatures of our interest, the quantum effects of molccular rotation are not pronounced. The rotational levels tend to establish an equilibrium among themselves very quickly, for example, within 20 collisions in nitrogen, and their distribution can be described by a rotational temperature, $T_{R}$. Because of a "near-classical" nature of the rotation, a vigorous exchange between the translational and rotational degrec of freedom occur during collisions. As a result, the rotational temperature tends to follow the translational temperature. However there arc cxperimental evidences (refs. 4 and 5) indicating that the rotational temperature may lag behind the translational temperature for quite some distance in a flow behind a strong shock. Thus, for example in general one needs to define $\mathrm{T}_{R}$ and $\mathrm{T}$ separately.

To first order, the nonequilibrium vibrational population may be described by a single vibrational temperature, $\mathrm{T}_{v}$. However, recent computations show that during relaxation the vibrational states, with the except ion of lowest levels, maintain a high degree of nonequilibrium 
among themselves and it is not possible to define a single vibrational temperature for all the vibrational levels. Therefore, whenever it is possible, one should use multi-vibrational tcmpcrature description of the gas medium.

Once the vibrational temperature $T_{v}$, the rotational temperature $T_{R}$, the electron temperature, $T_{e}$ and the translational temperature, $T$ are given, all that remains is to determine the populations in the electronic states. To do this, a set of equations similar to equation (4) are solved. An effective rate cocficient $K(i, j)$ for $i \rightarrow j$ electronic transition is defined by summing up the rate cocfficient for one rotational-state-to-rotational-state transition, $K\left(J, J^{\prime}\right)$ over all final vibrational and rotational states of ith electronic level and averaged over the initial vibrational and rotational states of the jth electronic level (ref. 7). It is also assumed that the electrons are ineffective in causing rotational quantum changes and the cross section for the $J \rightarrow J^{\prime}$ transition is the product of the Frank-Condon factor and an electronic part, independent of either vibrational or rotational quantum numbers. The excitation cross section for air molecules has been measured (refs. 40 and 43-46) for $\mathrm{T}_{v}=\mathrm{T}=\mathrm{T}_{R}=300 \mathrm{~K}$ for almost all transitions in which the initial state is the clcctronic ground state and are of the order of $10^{-17} \mathrm{~cm}^{2}$, except for $\mathrm{N}_{2}^{+}$, for which it is about $10^{-16} \mathrm{~cm}^{2}$. This room temperature data can be cxtended to any arbitrary combination of $\mathrm{T}, \mathrm{T}_{v}, \mathrm{~T}_{R}$ and $\mathrm{T}_{e}$ using the standard formulation (ref. 7). However, extending the room temperature data to the high velocity low density $\left(\mathrm{U}_{s}>10.0 \mathrm{~km} / \mathrm{sec}, \mathrm{p}_{1}<0.1\right.$ Torr) by using these standard formulations may lead to errors. For transitions in which the ground state is not the initial state, the cross sections are not known and they are assumed to be the same as the known cross sections with the same final state.

For conditions where the clectron mole fraction is at least $0.01 \%$, the electrons play the dominant role in the excitation of electronic states (eq. (4)). However at the low end of electron densities, the excitation by heavy-particle impact may be significant.

Some electronic states, such as the $C^{3} \Pi_{u}$ state of $\mathrm{N}_{2}$ (upper state of $\mathrm{N}_{2}\left(2^{+}\right)$band system) and the $B^{3} \Sigma_{u}^{-}$state of $\mathrm{O}_{2}$ (upper state of Schumann-Runge Band System), need special treatment. They lic above the dissociation limit. Because they are so high, collisional excitation from the lower electronic states is unlikely. Instead, they are populated by collisions between atoms through a process called predissociation. Depopulation is by the reverse process of predissociation and by radiative decay. By applying the principle of detailed balance (ref. 7) one obtains the populations in the two states. As mentioned above, the populations of other states are determined by solving the QSS equations in NEQAIR.

From each electronic state of a molecule, dissociation by heavy particle impact occurs (clectrons are less efficient in this regard). Available rate data (ref, 47) can be utilized in deducing the rate coefficients for collisional dissociation from various electronic states.

The radiative transition probabilities for molecules are also available in the literature (rofs. 48 and 49). 


\section{NONEQUILIBRIUM CHEMISTRY}

\section{A. Reaction Rates}

The gas medium, around hypersonic vehicles or in a hypersonic nozzle, most often, is a mixture of atoms and molecules. Under extreme temperature, they undergo a complex chain of chemical as well as thermodynamic interactions. As mentioned before, under nonequilibrium the populations of individual species, which are numerous, remain functions of time (or distance). For synthetic air $\left(78 \% \mathrm{~N}_{2}, 22 \% \mathrm{O}_{2}\right)$ computations, one has to consider about 11 dominant species involved in about 22 different chemical and radiative processes and for a more realistic air composition $\left(78 \% \mathrm{~N}_{2}, 21 \% \mathrm{O}_{2}, 0.93 \% \mathrm{~A}\right.$ and $0.03 \% \mathrm{CO}_{2}$ ), one needs to consider 19 species with 38 processes. In order to compute the source term (net production rate) associated with the respective mass conservation equation for each species, one needs to know the reaction rates, as a rule, in a form similar to equation (2). The chemical rate data are available for only a few of these reactions from experiments; for the rest of the reactions educated gucsscs arc madc. Park (refs. 50 and 51), through an extensive study of flight and shock tube data, has compiled a set of chemical rate data (table 1, cq. (2)), which seems to simulate the thermochemical nonequilibrium in air, for shock velocities in the range of $6.0-10.0 \mathrm{~km} / \mathrm{sec}$ (with moderate ionization), reasonably well. However, whenever the thermodynamic conditions change above a ccrtain level, such as, the degree of ionization increases or new species are introduced (Martian atmosphere, for example) (ref. 52), the reaction rate data set invariably needs reexamination.

Another point of major concern is the nature of controlling temperature in equation (2) to bc used in high tempcrature noncquilibrium conditions. Park's average tempcrature model (ref. 29) for dissociative reactions (table 1) seems to work well in predicting the nonequilibrium phenomena up to shock velocities of $10 \mathrm{~km} / \mathrm{sec}$. The model allows dissociation of a molecule by both centrifugal tearing, caused by rotational motion, and vibrational breaking. The square root of $\mathrm{T}$ (the model assumes $\mathrm{T}_{R}=\mathrm{T}$ ) is a measure of the velocity associated with the rotational motion, whereas the square root of $\mathrm{T}_{v}$ is a measure of the velocity associated with the vibrational motion at the midpoint of its oscillations. The product conceptually represents an average energy level in phase space. In reactions where electrons are involved as the product of the reaction, it is recommended that $\mathrm{T}_{e}$ is used as the controlling temperature, such as in ionization or recombination processes (table 1).

In the absence of a sufficient number of electrons, the electronic excitation occurs primarily by collisions with heavy particles. Based on shock tube experiments, Lotz (ref. 53) has postulated that the cross section for electronic excitation by neutral species is zero at threshold and varies approximatcly as $\propto \sigma . \log _{e}(y) / y$, where $\sigma$ is a constant on the order of $10^{16} \mathrm{~cm}^{2}$ and $y$ is the ratio of the translational kinetic energy of the colliding particles to the threshold. For ionic molecules Lotz proposes that the cross-section is a constant (ref. 53). As an example of clectronic excitation by heavy particles, the formation of excited NO molecules at low velocitics in air (rcfs. 47, 54, and 55) can be cited. The threc body reactions $N+O+M \rightarrow N O^{*}+M$ 
leads to the excitation of the $\mathrm{A}$ and $\mathrm{B}$ electronic states of $\mathrm{NO}$, which are responsible for $\mathrm{NO}-\gamma$ and NO- $\beta$ band systems.

\section{B. Multi-Temperature Model}

We have seen that while computing nonequilibrium radiation, one has to conduct a rigorous book keeping of all the electronic levels, possibly a score of vibrational levels, and locally defincd rotational, vibrational and clectron temperatures. For flow computations, such a rigorous exercise for the internal energy quanta is prohibitively expensive and is not necessary. A simplified approach may be adequate. In this approach:

1. In addition to translational energy, we recognize three separate pools of internal cnergy: 1) rotational energy, 2) vibrational energy, and 3) electronic energy. All the species contribute to these common pools of internal energy. In a more rigourous approach each species may be assigned to separate pools of energies, which in turn can be summed up to provide a global set of internal energies.

2. Assign each pool of encrgy an associated distribution function and the respective temperature i.c. define the vibrational temperature $\mathrm{T}_{v}$, rotational temperature $\mathrm{T}_{R}$, electron temperature $\mathrm{T}_{e}$, electronic temperature $\mathrm{T}_{\text {elect }}$ and translational temperature $\mathrm{T}$.

3. Account for the interaction among the five pools of encrgy during the relaxation process.

Rotational relaxation- Due to the "classical" nature of the rotational energy, the rotational degrec of freedom participates in a vigorous encrgy exchange with the translation mode. With that in mind, it is often customary to assume $\mathrm{T}=\mathrm{T}_{R}$. However, in a more accurate model one may define a Landau-Teller type relaxation for the rotational energy:

$$
\frac{\partial e_{R}\left(T_{R}\right)}{\partial t}=\frac{e_{R E}(T)-e_{R}\left(T_{R}\right)}{\tau_{L R}}
$$

where $e_{R}$ is rotational encrgy defined at a rotational temperature, $\mathrm{T}_{R}$. The rotational relaxation parameter, $\tau_{L R}$ has becn measurcd expcrimentally for molecules like hydrogen (refs. 56 and 67). Data on air molecules are unavailable, primarily because the rotational temperature follows the translational temperature very closely and experimentally it is difficult to distinguish between them.

Vibrational relaxation The vilbrational relaxation rate proposed by Millikan and White (ref. 58) shows that the Landau-Teller formulation is accurate at temperatures up to $\approx 5000 \mathrm{~K}$, and holds reasonably good to approximately $\approx 8000 \mathrm{~K}$, although the equation tends to slightly underestimate the relaxation times at the higher temperature range. For higher temperatures the formula needs to be modificd to take account of two phenomena: (ref. 7) 
1) a limiting value of the cross section and 2) the diffusive nature of vibrational relaxation. The first modification arises from the fact that the Millikan and White correlation implies an unrealistically large cross section for vibrational relaxation at high temperatures. The correction is introduced in the form of a limiting cross section $\sigma_{v}$ and an effective relaxation time, $\tau_{L}^{\prime}$ is defined:

$$
\tau_{L}^{\prime}=\tau_{L}+\tau_{c}, \quad \tau_{c}=\frac{1}{\langle c\rangle \sigma_{v} N}
$$

where $\langle c\rangle$ is the thermal speed of the molecule and $N$ the number density of the colliding particle. The numerical value of the $\sigma_{v}$ is an unknown quantity and is adjusted to satisfy the existing experimental data. For air molecules, for example, $\sigma_{v}=10^{-17}(50,000 / T)^{2}$ gives satisfactory results (see fig. 2).

The correction for the diffusive nature of the vibrational relaxation is suggested as follows: (ref. 59)

$$
\frac{\partial e_{v}\left(T_{v}\right)}{\partial t}=\underbrace{\frac{e_{v E}(T)-e_{v}\left(T_{v}\right)}{\tau_{L}^{\prime}}}_{\text {Landau -Teller }} \underbrace{\left(\frac{T_{i}-T_{v}}{T_{i}-T_{v i}}\right)^{s-1}}_{\text {correction factor }}
$$

where the subscript $\mathrm{i}$ refers to the initial condition immediately behind the shock wave. The parameter $s$ is an increasing function of $\mathrm{T}_{i}$, the maximum value being 3.5. A bridging formula is proposed in the following form

$$
s=3.5 \exp \left(-5000 / T_{s}\right)
$$

where $T_{s}$ is the translational-rotational tempcrature immediately behind the normal shock wave.

A more accurate approach would be a bi-modal vibrational model. Theoretical investigations (ref. 20) show that during nonequilibrium the vibrational population can not be described by a single temperature. The high vibrational levels tend to cquilibrate among themselves and the free state very early during the relaxation, and are not in equilibrium with the other states. The lower levels follow the Landau-Teller type relaxation. This necessitates the introduction of a bi-modal vibrational model. This model may even account for the excess energy, which still remains unaccounted for in the present day hypersonic flow equations (rcf. 60).

Electron and electronic temperature- Electrons thermalize themselves very quickly; however, they do not exchange any appreciable energy by collision with heavy particles. Therefore, the electrons, whose distribution is described by an electron temperature, remain loosely coupled to the heavy spccics through vibrational and electronic excitation processes. As discussed earlier, the electrons dominate the electronic excitation process, and if one assigns an electronic temperature to the excited electronic populations, $\mathrm{T}_{\text {elect }}$, then the assumption $T_{e} \approx T_{\text {elect }}$ may be justified.

Early researchers suggested that a strong coupling exists between the electronic degree of freedom and the vibrational mode (ref. 61). This hypothesis is in accordance with the 
fact that the radiation is quenched more effectively by molecular than by atomic collisions (ref. 32). Faizullov (ref. 62), while using the sodium line reversal technique, found that the populations of excited sodium atoms were strongly coupled with the vibrational temperature of the nitrogen molecule. There are other indications (ref. 63) that a strong coupling between the electronic and vibrational modes exists.

The electrons are also very efficient in causing vibrational energy transitions in molecules. In such elcctron-vibration (c-V) processcs, multiple-level transitions also take place with significant frequency, contrary to the Landau-Teller formulation. Lee (ref. 64), using the excitation and de-excitation rate coefficients based on computational quantum chemistry (ref. 65), theoretically analyzed the role of electrons in the vibrational excitation of nitrogen molecules and has suggested the following expression for the time constant for the e-V process

$$
\begin{aligned}
\log \left(p_{e} \tau_{e}\right)= & 3.91\left(\log T_{e}\right)^{2}-30.36\left(\log T_{e}\right) \\
& +48.90, \quad 1000 \mathrm{~K} \leq T_{e} \leq 7000 \mathrm{~K} \\
\log \left(p_{e} \tau_{e}\right)= & 1.30\left(\log T_{e}\right)^{2}-9.09\left(\log T_{e}\right) \\
& +5.58, \quad 7000 \mathrm{~K} \leq T_{e} \leq 50000 \mathrm{~K}
\end{aligned}
$$

where $p_{e}$ is electron pressure and $\tau_{e}$ is the time constant. $\tau_{e}$ is to be used in the equation (7) in place of $\tau_{L}^{\prime}$ for the $\mathrm{c}-\mathrm{V}$ process.

As it is clear from the above discussion that in order to simplify the computation, in certain cases, $\mathrm{T}_{e}=\mathrm{T}_{\text {elect }}=\mathrm{T}_{v}$ is acceptable.

\section{COMPUTER CODES AND FLOW COMPUTATIONS}

Park's (ref. 7) NEQAIR program incorporates most of the physics discussed in Section II using the basic structure of a code written by Arnold et al. (ref. 31) Two computer codes have been written to couple the one-dimensional fluid equations with the nonequilibrium radiation physics (NEQAIR): 1) STRAP (Shock Tube RAdiation Program) for the shock tube flow behind a normal shock, and 2) SPRAP (Stagnation Point RAdiation program) for the stagnation strcamline in the shock layer over a blunt body. Park (refs. 59 and 66) has extensively used these codes to reproduce the experimental data (refs. 1-3, 9-15, and 67) taken in shock tubes, ballistic ranges, and flight experiments at shock velocities in the range of $6-10 \mathrm{~km} / \mathrm{sec}$. Park was able to reproduce most of the laboratory data, namely the 1) rotational temperature, 2) electronic excitation tempcrature, 3) temporal variation of radiation intensitics, 4) characteristic relaxation times, and 5) the ratio of nonequilibrium - to equilibrium-radiative heat fluxes (with the exception of vibrational temperature, which will be discussed later). In order to do that it was necessary to adjust the reaction rates, for which no experimental or analytical data are available, by trial and crror until a good agrecment between the theory and experiment was achicved. A set of reaction rates for air constituents used in these computations is given in table 1. 
Recently these program have been improved by Whiting (ref. 69) and combined into a single code. The improvements are: 1) generalization of chemical reaction schemes, 2) inprovement in the accuracy of partition functions and radiation calculation schemes, and 3 ) inclusion of the species $\mathrm{C}, \mathrm{CO}, \mathrm{CN}$, and $\mathrm{C}_{2}$ in the excitation calculations. All of thesc codes assume $\mathrm{T}_{\text {elec }}=\mathrm{T}_{e}=\mathrm{T}_{v}$ and $\mathrm{T}_{R}=\mathrm{T}$ in the fluid computations with the average temperature, $T_{a}=\sqrt{T T_{v}}$ in the rate equations (eq. (2)). Several two- and three-dimensional fluid codes coupled with NEQAIR have been developed over the years. Two of the most notable of these are a program by Candler (ref. 70) and the program LAURA (Langley Aerothermodynamic Upwind Relaxation Algorithm) by Gnoffo (ref. 71).

Chung Park (ref. 72) working on "Cassini" project extended the NEQAIR code to include methane, hydrogen and argon in order to simulate entry into Titans's atmosphere. His fluid code used a three temperature model i.e. $\mathrm{T}_{e}=\mathrm{T}_{\text {elec }} \neq \mathrm{T}_{v}$. Chung Park has also conducted cmission radiation measurements in gas mixtures simulating Titan's atmosphere and has compared them with his theoretical results. Nelson (ref. 73) also investigated the nonequilibrium radiation from Titans's atmosphere by extending the SPRAP code to a host of hydrocarbons as constituents.

For the simulation of low velocity rocket flights $(\approx 3.5 \mathrm{~km} / \mathrm{sec})$ Levin (ref. 54 ) has modified the NEQAIR code to include the electronic excitation of NO by heavy particle collisions and has compared the theoretical results with the flight data from the Bow Shock Ultraviolet Rockets (refs. 74 and 75) flights.

\section{COMPUTATIONAL RESULTS: DISCUSSION}

\section{A. Air Radiation}

(i) Low ionization flows $\left(N_{c} / N<0.01 \%\right)$ - At low velocities $(<5.0 \mathrm{~km} / \mathrm{sec})$, as discussed in Section III, the electron population may not be great enough to dominate the electronic and vibrational excitation process, and the heavy particle collisions play a major role. Since the excitation rates to discrete electronic levels of atoms and molecules by heavy particle collisions are not very well known, modelling of nonequilibrium radiation in this regime is difficult. Strong coupling of vibrational energy with the electronic states of atoms and molecules (refs. 32 and 61-63) further complicate the physics of nonequilibrium radiation. In Levin et al's computations (ref. 54) the electronic excitation of NO was modelled as a three body recombination process. The modified NEQAIR code was used to simulate the radiation recorded aboard the Bow Shock Ultraviolet Rocket flight experiment (ref. 74). The results show that the low altitude data $(\approx 40 \mathrm{~km}, \sim$ equilibrium regime) agree with the computed results. However, the predicted nonequilibrium radiation using a multi-temperature model $\left(\mathrm{T}_{R} \neq \mathrm{T}\right.$ ) was lower by as much as 4 orders of magnitude (at $\sim 60 \mathrm{~km}$ ).

A possible explanation can be provided as follows. In recent shock tube cxperiments at Calspan (ref. 76), conducted at shock velocities in the $3.22-3.83 \mathrm{~km} / \mathrm{sec}$ range, it was found that in the absence of NO, the vibrational temperature of $\mathrm{N}_{2}$ (infrared measurements at $5 \mu$ ) 
shows a slow approach to its equilibrium value, in a manner NEQAIR predicts. In other words, the modelling of $\mathrm{N}_{2}$ excitation in NEQAIR is reasonably accurate. As soon as NO forms in the flow, the vibrational temperature shoots up rapidly much faster than exhibited by $\mathrm{N}_{2}$ vibrational temperature. It seems that $\mathrm{NO}$ molecules are probably produced in a vibrationally excited state. Possible mechanisms may be the formation of $\mathrm{NO}$ in reactions where the kinetic and chemical energies are directly converted into vibrational energy during the collisions. The vibrationally excited, ground electronic NO molecules may in turn interact to produce excited A-state molecules. This hypothesis seems to be in good agreement with the expcrimental findings about the strong couplings between vibrational and electronic states.

This area of molecular excitation needs further work. Without a better understanding of these phenomena, our capability to compute nonequilibrium radiation at low velocities will not improve.

(ii) Moderate ionization (3\% $\left.>N_{e} / N>0.01 \%\right)$ - Most of the theoretical and experimental investigation on nonequilibrium radiation has been conducted in this regime. The low end, for example, may correspond to a shock velocity of $6.0 \mathrm{~km} / \mathrm{sec}$ in 1 Torr air and the high end to a shock velocity of $10.0 \mathrm{~km} / \mathrm{scc}$ into 0.1 Torr air. Spectral calculation of emitted nonequilibrium radiation is conducted by many investigators (refs. 1-5, 59 and 66) and compared with the available experimental data. The spectral data primarily have been recorded in shock tube experiments. The spectra at these conditions consists of NO- $\beta, \mathrm{N}_{2}^{+}\left(1^{-}\right), \mathrm{N}_{2}\left(2^{+}\right)$ and $\mathrm{N}_{2}\left(1^{+}\right)$band systems. Typical equilibrium and nonequilibrium spectra recorded at a shock velocity of $10 \mathrm{~km} / \mathrm{sec}$ in 0.1 Torr air (ref. 5) are shown in figures 3 and 4 . As illustrated in figure 1 the nonequilibrium overshoot is very pronounced at these velocities. The ratio of pcak noncquilibrium radiation to the cquilibrium radiation $\left(I_{p} / I_{e}\right.$, fig. 1 (c)), from various shock tube experiments are plotted in figure 5. Four sets of the data: 1) at $4.75 \mathrm{~km} / \mathrm{sec}$ in 10 Torr $\mathrm{N}_{2}, 2$ ) at 5.54 in 3 Torr $\mathrm{N}_{2}, 3$ ) at $6.4 \mathrm{~km} / \mathrm{sec}$ in 1 Torr $\mathrm{N}_{2}$, and 4) at $10 \mathrm{~km} / \mathrm{sec}$ in 0.1 Torr air, were recorded by Allen et al ${ }^{1}$ at AVCO Everett Research Laboratories, MA. The other two sets: 1) at $6.2 \mathrm{~km} / \mathrm{sec}$ in 1 Torr $\mathrm{N}_{2}$, and at $10 \mathrm{~km} / \mathrm{sec}$ in 0.1 Torr air, were recorded by the author and co-workers at NASA Amcs (ref. 4 and 5). AVCO's data were obtained by integrating the spectral cmission data in the $5500-10000 \AA$ wavelength range and NASA Ames's data were integrated in the 3100-7100 $\AA$ range. The computed values for these conditions using STRAP's two temperature model, $T_{a}=\sqrt{T T_{v}}$ for chemical nonequilibrium, also have becn plotted in the figurc. It should be remembered that for the computation of radiation STRAP uses NEQAIR, which models the electronic states of each species using a multi-temperature approach. The good agrecment between the theory and the experimental data demonstrate that the physical model presented here simulates the radiation nonequilibrium at moderate ionization with reasonable accuracy. It should be noted that the degree of noncquilibrium enhancement over its equilibrium value increases with increase in the shock velocity. At a certain shock velocity, most likely between 7 and $9 \mathrm{~km} / \mathrm{sec}\left(\mathrm{p}_{1} \approx 0.1\right.$ Torr), $I_{p} / I_{c}$ achieves a peak value and starts to drop. At $10 \mathrm{~km} / \mathrm{sec}$ in 0.1 Torr air the ratio, $I_{p} / I_{e}$ drops to $\approx 4.5$. It is important to note that at a given velocity the ratio, $I_{p} / I_{e}$ is strongly dependent on the initial pressure before the shock. 
As discussed before, the "binary scaling law" dictates that the nonequilibrium-toequilibrium radiative heat flux defined as

$$
\frac{\int_{0}^{t_{0.1}} I d t}{I_{e} \cdot t_{0.1}} \quad \text { (see fig. 1) }
$$

is a quantity independent of the initial pressure. Experimental values of this heat-flux ratio as function of shock velocity are compared with the computed values in figure 6 . Once again a good agrecment between the theory and the experiments is scen.

The ability of the present model to compute detailed spectral radiation is put to test in figure 7 , in which the experimental spectral emission data(refs. 1 and 5) at the point of pcak intensity are compared with the synthetic spectrum produced by the STRAP code. The spectra are for a shock velocity of $10 \mathrm{~km} / \mathrm{sec}$ in 0.1 Torr air. The synthetic spectrum is corrected for the instrument broadening by the input slit. The synthetic spectrum overestimates the emission in the UV $(0.3-0.5 \mu \mathrm{m})$ range and slightly underestimates in the infrared $(0.55-1.5 \mu \mathrm{m})$. The AVCO data show even lower emission in the UV range and higher emission in the infrared range when compared with the NASA Ames's data. The overestimate of the UV cmission, which is duc to the $\mathrm{N}_{2}^{+}\left(1^{-}\right)$band system, could be caused by: 1) uncertainty of total $\mathrm{N}_{2}^{+}$population estimates $(\approx 50 \%), 2$ ) effect of rotation on the dissociation process, and 3 ) the vibrational temperature may be too high. Recently, in temperature measurements at the point of peak radiation in nitrogen ${ }^{4}$ and in air $^{5}$ it was found that the rotational temperature was considerably lower than the translational temperature (fig. 8). This invalidates the assumptions $T_{R}=T$ made in STRAP and SPRAP codes and leads us to believe that a relaxation model for the rotational energy (eq. (6)) should be considered.

The vibrational temperature of the species during the nonequilibrium is another matter of concern. In figure 9 the vibrational temperature measured by Allen (ref. 77) and by the Author ${ }^{4}$ are plotted against the theoretical prediction for nitrogen $(6.2 \mathrm{~km} / \mathrm{sec}, 1$ Torr $)$. Two points should be made regarding this data. First, there is obviously a discrepancy between the AVCO and The NASA Ames's data. Sccond, and perhaps more important, the vibrational temperatures measured at NASA Ames for $\mathrm{N}_{2}\left(2^{+}\right)$and $\mathrm{N}_{2}^{+}\left(1^{-}\right)$are different in the same experiment. This result is not unexpected, since a single vibrational temperature does not necessarily exists for all species. Most likely the high vibrational states of $N_{2}^{+}\left(B^{2} \Sigma_{u}^{+}\right)$tend to be in cquilibrium with the free state $\left(N_{2}^{+}\left(B^{2} \Sigma_{u}^{+}\right) \rightleftharpoons N+N^{+}\right)$. Park (ref. 50) determined a vibrational temperature, $\mathrm{T}_{v}^{*}$, describing the local equilibrium among high vibrational states and the free state, to be different from the ground state $\mathrm{T}_{v} \cdot \mathrm{T}_{v}^{*}$ computed this way follows the slow rise in the vibrational temperature measured by AVCO (fig. 9). To summarize, it can be stated that in gencral: 1) two different vibrational temperatures may exist, one for the ground states and another for the higher states, and 2) there may be different sets of two vibrational temperatures for each of the dominant species.

The discussion of our present capabilities to compute radiation cmission from high temperature air can be divided into two subgroups:

a. Equilibrium radiation: The radiation plateau reached after the nonequilibrium overshoot is most often believed to be caused by the onset of equilibrium in the gas. In fact, it 
is due to the attainment of a steady state in which the populations in some of the higher electronic states may still remain much different from those of their equilibrium values. At low velocities $(\sim 6.0 \mathrm{~km} / \mathrm{sec})$ the radiative emission from this steady state is not very different from equilibrium air. However, at higher velocities and low densities $(\sim 10.0 \mathrm{~km} / \mathrm{sec})$ the difference becomes significant. It is interesting to note that this difference between the steady state and equilibrium emission is not uniformly distributed over the entire spectral range. $\mathrm{N}_{2}^{+}$ molecules contributing to the most prominent radiator, the First Negative Band System, seem to cquilibrate near the plateau and hence the steady state and equilibrium emissions from this band system are ncarly the same. It should be noted here that $\mathrm{CN}$ violet radiation can significantly alter the appearance of the $\mathrm{N}_{2}^{+}\left(1^{-}\right)$band system, especially the $(0,0)$ band system at $3882.6 \AA$ and the $(1,0)$ band system at $3582.1 \AA$. Experiments (ref. 5) show that equilibrium radiation from $10 \mathrm{ppm} \mathrm{CN}$ impurity in the shock tube can be of the same magnitude as the emission from the $\mathrm{N}_{2}^{+}\left(1^{-}\right)$band systcm. However, if the level of the impurities is properly accounted for, the agreement between the experiment and theory is excellent (ref. 78).

On the other hand, at velocities higher than $10.0 \mathrm{~km} / \mathrm{sec}$ and low densities, NEQAIR predicts much higher radiative cmission from most of the atomic systems than measured experimentally. The discrepancy between the computations and the experiments does not seem be uniformly distributed over any particular atomic system, not even in the same multiplet system. For example, the computed emission from the $4 \mathrm{p}{ }^{4} S^{\circ} \rightarrow 3 s^{4} P$ nitrogen triplet system at $4151.46,4143.42$ and $4137.63 \AA$ falls, on average, within a factor of 5 of the experimental data. However, for the $4 \mathrm{p}^{4} P^{o} \rightarrow 3 s^{4} P$ multiplet system the computed values average about 50 times higher than the experimental values. Individually, in the $4222.73,4223.04$ and $4224.74 \AA$ triplet system, the computed values are about $61,10.2$ and 51 times higher than the expcrimental data, respectively (ref. 78). This large scatter in the discrepancies between thcory and experiment persists cven if a Boltzmann excitation is assumed. Two possible explanations are proposed:

1. NEQAIR assumes that closely packed energy level achieve a local equilibrium during the relaxation process almost instantaneously and for that reason they are grouped together to form onc pscudo state to simplify the QSS solution. It is possible that individual states of these multiplet systems, no matter how unlikely it may seem, populate and relax at different rates than their neighbors. If so, then one must formulate the QSS problem by accounting for all the relcvant energy levels.

2. The published ' $\mathrm{f}$ ' numbers of the individual states used in NEQAIR may not be accurate. Most of the ' $f$ ' number data are obtained in a high current high pressure discharge where most spectral lines are broad. In a multiplet system, it is often not possible to distinguish between the adjacent spectral lines under these experimental conditions. For simplicity, the contributions of individual lines in the multiplet system are assumed to be distributed according to the l-s coupling. The emission experimental data (ref. 5) under low density high temperature conditions indicate that this may not be the case. Also ' $f$ ' number measurements are conducted under high elcctromagnetic forces. It is not clear how the 'effective' value of ' $f$ ' numbers 
will change, if any, under the relatively low ionization found in hypersonic flows. In any case, ' $f$ ' numbers of the appropriate energy levels need to be investigated further.

Also at velocities above $10 \mathrm{~km} / \mathrm{scc}$, the computed values of radiative emission from $\mathrm{N}_{2}$, are a few hundred times less than observed in the experiments. The under prediction from $\mathrm{N}_{2}$ band systems makes sense in the following way. The molecular populations in certain clectronic states may attain equilibrium with certain electronically excited free states (atoms). As a result, the code, on one hand overpredicts the atomic radiation and, at the same time, underpredicts the molecular radiation. This suggests that, in the experiments, the molecular populations in certain excited electronic states are lower than their equilibrium values and the atomic populations in certain the excited electronic states are higher. Although, at this stage the overall population of molecules and atoms are also in equilibrium at the temperature of equilibration $\left(\mathrm{T}=\mathrm{T}_{R}=\mathrm{T}_{v}=\mathrm{T}_{e}\right)$, experimental data suggest the distribution of electronic states still remains far from equilibrium.

b. Nonequilibrium radiation: Emission in the nonequilibrium regime shows ncarly the same bchavior. At low velocitics and higher densities (for example, at $6.0 \mathrm{~km} / \mathrm{sec}$ in 1 Torr) the agrecment between the experimental values and the prediction is reasonably good. At higher velocities and low densities (for example, at $10.2 \mathrm{~km} / \mathrm{sec}$ in 0.1 Torr) the predicted emission from the $\mathrm{N}_{2}^{+}$band systems also agrees well with the experiments, provided the impurities like $\mathrm{CN}$ are properly accounted for. The level of impurities added in the computations to reconcile with the experimental data, however, are one to two order of magnitude lower than that required in the equilibrium case.

As in the case of equilibrium radiation, at low densities and higher velocities the code under predicts the $\mathrm{N}_{2}$ Second Positive and First Positive band systems and over predicts most of the $\mathrm{N}$ and $\mathrm{O}$ atomic systems. The code underpredicts the $\mathrm{N}_{2}$ band radiation by about an order of magnitude and the overprediction of atomic radiation is about an order of magnitude less than in the equilibrium case. If all the collisions mechanisms are the same as in the equilibrium regime, radiative decay proccsses may be playing a dominant role in this regime and radiative life times may be comparable with the relaxation times.

Beside the laboratory data, there are a host of flight data against which the nonequilibrium radiation model has been tested. Among the most notable flight data are: 1) Project FIRE 1 (ref. 11) and FIRE 2 (ref. 12) data, 2) Planetary Experiment Test (PAET) (refs. 10 and 68) data, 3) Apollo 4 and 6 data (refs. 13 and 14). Flight experiments, unlike laboratory data, as a rule, provide data on bulk properties, such as integrated heat loads using calorimeters and radiometers. Apart from the flight altitude conditions (such as temperature, collision limiting etc.) the data is also affected by the phenomena caused by the vehicle's geometry (such as truncation, ablation etc.). Also, since the vehicle fies in a real atmosphere, the trace elements found at the flight altitude may add additional complexities to the radiative heat transfer such as, observance of CN violet in PAET flights. Therefore, one must take these physical phenomena into account when analyzing the flight data. When one uses the flight data to validate or verify the physics of the nonequilibrium radiation, the added affects make the process more complex and the verification less convincing. At the same time, some of these 
effects, such as collision limiting and truncation, provide another dimension in the verification process.

The FIRE vehicles were approximately $1 / 4$-scale models of the Apollo command module and entered the atmosphere at velocities slightly higher than those of Apollo vehicles. The vehicles were made of beryllium and hence not ablating. The measured convective heat transfer agreed well with the available theories. The radiation data, at low altitudes, were in agrecment with the equilibrium radiation computations. At higher altitudes, the radiative hcating violated the "binary scaling law" and varied with diminishing density. However, if one takes "truncation" into account, it is possible to reproduce the flight data for a certain range of the flight (fig. 10). Due to the small size of the vehicle, many phenomena, such as viscous effects, finite shock thickness, small shock stand-off distance etc., play a role in the radiative transport. Therefore, only a portion of the flight data can be used to validate the physical model presented here.

Over the years, attempts to reproduce the flight data mentioned here have been partially successful. The general consensus is that the true extent of nonequilibrium radiation in FIRE and Apollo experiments was not realized at the time.

The preceding comparisons of experimental data and the theoretical prediction, in the moderately ionized regime, show that this model is fairly accurate in reproducing most of the experimental data. The model is reasonably accurate in reproducing integrated radiation intensities, and reproduces the spectral data at low velocities and high densities with acceptable accuracy. The model, however, does only a fair job of reproducing spectral data obtained in the ground tests at low density and high velocity.

(iii) High degree of ionization $\left(N_{e} / N>3 \%\right)$ The radiation emission in this regime is dominated by free-free transitions, bound-free transitions and strong atomic line radiation. Depending upon the optical path the atomic line tend to be self-absorbed in the media. Thus, in a moderately optically thick medium, which is a morc rcalistic scenario for this regime, complex line by line spatial integration is required. In an optically thick approximation, of course, only free-free and bound-free radiation necd to be considered. Therefore, emphasis of the model in this regime is more on the accuracy of radiative transport computations than on the chemical and/or thermodynamic nonequilibrium model. Because of high electron density, more charge transfer and associative ionization reactions are added to the list of chemical reaction given in table 1 (ref. 52).

In the highly ionized regime the nonequilibrium overshoots tend to decrease with increase in the shock velocity (fig. 5) leading to an undershoot. Such an undershoot can be secn in Wilson's work (ref. 78), which is one of the very few experimental investigations available for this regime. With the selection of proper reaction rates (ref. 52), and by accounting for the alleged impurities in the experiments, the general trend of Wilson's data can be reproduced qualitatively by the present model (fig. 11). Since the emission in this regime is proportional to $N_{e}^{2}$, the plot in figure 11 is shown in terms of $N_{e}^{2}$. 
For the verification of computed spectral intensities, reliable and complete experimental data sets for this regime are not available. Depending upon the integration scheme in the radiative transport bookkeeping, discrepancies up to several orders of magnitude have been found in the spectral intensities. Even the integrated radiation heat flux, which under the "binary scaling law," should be density independent, has been found to scatter as much as one order of magnitude, depending on the method of computation. With a concerted effort in radiative transport integration techniques and the acquisition of reliable and complete spectral and integrated radiation data, our computational capabilities for this regime will be improved.

\section{B. Martian Atmosphere}

The Martian atmosphere consists of $95.7 \% \mathrm{CO}_{2}, 2.7 \% \mathrm{~N}_{2}$ and $1.6 \% \mathrm{Ar}$ (ref. 79). Therefore, a shock layer in the Martian atmosphere will contain $\mathrm{C}, \mathrm{CO}, \mathrm{C}_{2}$ and $\mathrm{CN}$, all of which have mechanisms for strong radiation. Of particular interest are the Fourth positive system of $\mathrm{CO}$, the Red and Violet systems of $\mathrm{CN}$, the Swan system of $\mathrm{C}_{2}$, and atomic lines of $\mathrm{C}$ and $\mathrm{O}$. Reaction rates for various dissociation, ionization and vibrational relaxation of $\mathrm{CO}_{2}, \mathrm{CO}$ and $\mathrm{N}_{2}$ are available in the literature (refs. 80-84). Fair amounts of theoretical and experimental data on the vibrational relaxation of various mixtures of $\mathrm{CO}_{2}$ and $\mathrm{CO}$ have been made. The observed relaxation can be represented with reasonable accuracy by Millikan and White formula. A considerable amount of experimental data, valid for temperatures upto $15,000 \mathrm{~K}$, exist (refs. 82 and 83) on dissociation of $\mathrm{CO}_{2}, \mathrm{CO}$ and $\mathrm{CN}$ and on exchange reactions containing these gases. Most of the high temperature experimental data are available for collisions with argon. The rates for collisions with other molecules and atoms are assumed (ref. 82) to be about 10 and 15 times higher than that measured in argon, respectively. Using these, tentative reaction rates applicable to Martian atmosphere can be compiled (sec ref. 52).

The entry velocity into the Martian atmosphere range from 6-9 km/sec. No kinetic or radiation measurements have yet been made in the Martian gas mixtures. However, some theoretical and experimental investigations (ref. 85-91) have been made in various mixtures of $\mathrm{CO}_{2}, \mathrm{CO}$ and $\mathrm{N}_{2}$. These data can be used to assess the present model for calculation in the Martian atmosphere. In figure 12, the calculated equilibration distance (distance traveled in time $t_{0.1}$, fig. 1 ), reproduced here from reference 52 , is shown and compared with the experimental data and other theoretical predictions for a post shock pressure of $0.15 \mathrm{~atm}$. The prediction from reference 52 secms to agree with the experimental data of Arnold and Nicholls (ref. 86) approaching the mean value of Nealy's data (ref. 88). Also it agrees with Howe's (ref. 89) theoretical prediction.

The computed valucs of radiative heat flux have been found to be very sensitive to line shapes of the transitions. In an optically thick environment, if one assumes a thin line, its center region, which contains most of the radiative energy, is self absorbed and the net radiative energy to the wall, contributed by the wings of the line, is bound to be smaller than in an optically thin gas. However, if onc assumes a thick line, due to the smearing effect, the integrated area under the wings becomes appreciably larger than the thin line case. As a result, the computations estimate a larger heat flux to the wall under the thick line assumption. 
Computations show that for flight velocity of 6-9 km/sec, the predicted equilibration distance varies between 9 and $27 \mathrm{~cm}$. Thus, computations of the radiative heat load on an entry vehicle whose shock stand off distance is in the 9-27 cm range (or less), require the nonequilibrium radiation model. An equilibrium model will under predict the radiative heat load in those cases.

\section{Titan Atmosphere}

The atmosphere of Titan is known to be composed of molecular nitrogen, methane, hydrogen and possibly argon. However, the specific mole fractions of the constituents are not well known (ref. 92). For the heat load analysis (ref. 72), a composition of $95.7 \% \mathrm{~N}_{2}, 3.0 \%$ $\mathrm{CH}_{4}, 1 \%$ argon and $0.3 \%$ hydrogen and an entry velocity in the range of 5-7 km/sec has been assumed. Under these conditions $\mathrm{CN}$ will readily be formed and is considered the dominant radiator along with minor contributions from $\mathrm{C}_{2}$ Swan band system. A list of chemical reactions and the reaction rates needed for the computations of radiative heating load in Titan's atmosphere has been compiled by C.P. Park (ref. 72) and Nelson (ref. 73). C. P. Park also conducted emission measurements in a shock tube. He produced the $\mathrm{CN}$ emission data using a three temperature $\left(\mathrm{T}, \mathrm{T}_{v}\right.$ and $\left.\mathrm{T}_{e}\right)$ and the average temperature $T_{a}=\sqrt{T T_{v}}$ model for the chemical processes and a modified NEQAIR code for the radiation calculations.

\section{CONCLUSIONS}

Based on our current understanding of the nonequilibrium phenomena, our computing capability, and the role of radiative transport and the thermochemistry in the physical model, we may divide the hypersonic flows into three groups: 1) low ionization flows, $N_{e} / N<0.01 \%$, 2) moderate ionization flows, $3 \%<N_{e} / N<0.01 \%$ ), and 3) highly ionized flows.

Our basic understanding of noncquilibrium radiation in the low ionization flows is rather poor. The role of heavy particles in electronic excitation and the coupling between the vibrational and electronic energy modes are, especially, not well understood. There is evidence that the published data on ' $\mathrm{f}$ ' numbers for certain transitions may not be applicable to the regime of hypersonic flow. Also it scems that the QSS formulations performed for computing radiative emission (or absorption) must be extended to a larger number of energy levels. The cxpcrimental data being gathered at the E.A.S.T. Facility of NASA Ames Research Center have a wealth of information on these radiative processes. A thorough analysis of the data will improve our understanding of the relevant mechnisms leading to the development of improved codes.

The flows with moderate ionization are the most researched, and most understood. The spectral cmission radiation for this regime can be computed with reasonable accuracy. The computed total integrated radiative heat flux from the shock layer for this regime agrees well with the shock tube, ballistic range and, in most cases, flight data. Other parameters, 
such as the relaxation time and equilibration distance are also in good agreement with the experimental data.

Our ability to compute the nonequilibrium radiation from highly ionized flows is also poor. The problem lies, not as much in the basic understanding of the physics involved, but in the complex bookkeeping of the radiative transport phenomena. Due to the significant degree of radiative cooling, radiative transport calculations must be done with improved accuracy. Also, reliable experimental data against which the computations can be verified, are limited in number. A low density shock tube facility is under development at the E.A.S.T. Facility of NASA Ames Research Center to address this problem.

The computation of radiation from planetary atmospheres other than air is, in principle, within our present day capabilities, since these flows fall into one of the last two categories: moderately and highly ionized. Experimental data, however, are needed for verification purpose. 


\section{REFERENCES}

1. Allen, R. A.; Rose, P. H.; and Camm, J. C.: Nonequilibrium and Equilibrium Radiation at Super-Satellite Re-entry Velocities, AVCO Everett Research Laboratory, Everett, MA, Research Report 156, Sept. 1962.

2. Teare, J. D.; Georgiev, S.; and Allen, R. A.: Radiation from the Nonequilibrium Shock Front, AVCO Everett Research Laboratory, Everett, MA, Research Report 112, Oct. 1961.

3. Camm, J. C.; Kivel, R. L.; Taylor, R. L.; and Teare, J. D.: Absolute Intensity of Nonequilibrium Radiation in Air and Stagnation Heating at High Altitudes, AVCO Everett Research Laboratory, Everett, MA, Research Report 93, Dec. 1959.

4. Sharma, S. P.; and Gillespie, W. D.: Nonequilibrium and Equilibrium Shock Front Radiation Measurements. J. Thermophysics and Heat Transfer, vol. 5, no. 3, pp. 257-265, July 1991. Also AIAA Paper 90-0139, January 1990.

5. Sharma, S. P.; Gillespie, W. D; and Meyer, S. A.: Shock Front Radiation Measurements in Air. AIAA Paper 91-0573, January 1991.

6. Howe, J. T.: Introductory Aerothermodynamics of Advanced Space Transportation Systems. J. Spacecraft and Rockets, vol. 22, no. 1, pp. 19-26, Jan.-Feb. 1985.

7. Park, C., Calculation of Nonequilibrium Radiation in the Flight Regimes of Aeroassisted Orbital Transfer Vehicles. Progress in Aeronautics and Astronautics: Thermal Design of Aeroassisted Orbital Transfer Vehicles, vol. 96, edited by H.F. Nelson, American Institute of Aeronautics and Astronautics, New York, N. Y., pp. 395-418, 1985.

8. Park, C.: Radiation Enhancement by Nonequilibrium in Earth's Atmosphere, J. Spacecraft and Rockets, vol. 22, no.1, Jan.-Feb. 1985, pp. 27-36.

9. Page, W. A.; and Arnold, J. O.: Shock Layer Radiation of Blunt Bodics at Entry Velocities, NASA TR R-193, 1964.

10. Seiff, A.; Reese, D. E.; Sommer, S. C.; Kirk, D. B.; Whiting, E. E.; and Niemann H. B.: PAET, An Entry Probe Experiment in the Earth's Atmosphere, ICARUS, vol. 18, no. 4, pp. 525-563, 1973.

11. Cauchon, D. L.: Project Fire Flight 1 Radiative Heating Experiment, NASA TM-X-1222, 1966.

12. Cauchon, D. L.: Radiative Heating Results from the Firc 2 Flight Experiment at a Reentry Velocity of 11.4 Kilometers per Seconds, NASA TM-X-1402, 1967. 
13. Lee, D. B.; and Goodrich, W. D.: The Aerothermodynamic Environment of the Apollo Command Module during Super-Orbital Entry, NASA TN D-6792, 1972.

14. Curry, D. M.; and Stephens, E. W.: Apollo Ablator Thermal Performance ar SuperOrbital Entry Velocities, NASA TN D-5969, 1970.

15. Shirai, H.; and Park, C.: Experimental Studies of Radiative Base Heating of a Jovian Entry Model. Progress in Astronautics and Aeronautics: Entry Heating and Thermal Protection, vol. 69, edited by W. B. Olstad, American Institute of Acronautics and Astronautics, New York, N. Y., pp. 148-171, 1980.

16. Park, C.: Calculation of Radiation From Argon Shock Layers. J. Quantitative Spectroscopy and Radiative Transfer, vol. 28, no. 1, pp. 29-40, Jan. 1982.

17. Arnold, J. O.; and Whiting, E. E.: Nonequilibrium Effects on Shock-Layer Radiometry during Earth Entry. J. Quantitative Spectroscopy and Radiative Transfer, vol. 13, pp. 861-870, 1973.

18. Cooper, D. M.; Jaffe, R. L.; and Arnold, J. O.: Computational Chemistry and Aeroassisted Orbital transfer Vchicles. J. Spacecraft and Rockets, vol. 22, no. 1, pp. 60-67, Jan.-Feb. 1985.

19. Menees, G. P.: Thermal-Protection Requirements for Near-Earth Acroassisted OrbitalTransfer Vehicle Missions, AIAA Paper 83-1513, AIAA 18th Thermophysics Conference, Montreal, Canada, June 1983.

20. Sharma, S. P.; Huo, W. M.; and Park, C.: The Rate Parameters for Coupled VibrationDissociation in a Generalized SSH Approximation. J. Thermophysics and Heat Transfer, vol. 6, no. 1, pp. 9-21, January 1992.

21. Sharma, S.: Vibrational and Rotational Temperature Measurements in a Shock Tube, 18th International Symposium on Shock Waves, July 21-26, 1991, Sendai, Japan.

22. Park, C.: Problems of Rate Chemistry in the Flight Regimes of Aeroassisted Orbital Transfer Vehicles. Progress in Acronautics and Astronautics: Thermal Design of Acroassisted Orbital Transfer Vehicles, vol. 96, edited by H.F. Nelson, American Institute of Aeronautics and Astronautics, New York, N. Y., pp. 511-537, 1985.

23. Wray, K. L.: Shock-Tube Study of the Coupling of the $\mathrm{O}_{2}-\mathrm{A}_{r}$ Rates of Dissociation and Vibrational Relaxation. J. Chemical Physics, vol. 37, pp. 1254-1263, 1962.

24. Hammerling, P.; Teare, J. D.; and Kivel, B.: Theory of Radiation from Luminous Shock Waves in Nitrogen. Physics of Fluids, vol. 2, pp. 422-426, 1959.

25. Treanor, C. E.; and Marronc, P. V.: The Effect of Dissociation on the rate of Vibrational Rclaxation. Physics of Fluids, vol. 5, pp. 1022-1026, 1962. 
26. Marrone, P. V.; and Treanor, C. E.: Chemical Relaxation with Preferential Dissociation from Excited Vibrational Levels. Physics of Fluids, vol. 6, pp. 1215-1221, 1963.

27. Treanor, C. E.: Vibrational Energy Transfer in High-Energy Collisions. J. Chemical Physics, vol. 43, pp. 532-538, 1965.

28. Treanor, C. E.; Rich, J. W.; and Rchm, R. G.: Vibrational relaxation of Anharmonic Oscillators with Exchange-Dominated Collisions. J. Chemical Physics, vol. 48, pp. 1798-1807, 1968.

29. Park, C.: Convergence of Computation of Chemically Reacting Flows. Progress in Astronautics and Aeronautics: Thermophysical Aspects of Re-Entry Flows, vol. 103, Edited by Jim Moss and Carl D. Scott, AIAA, New York, pp. 478-513, 1986.

30. Park, C.: Comparison of Electron and Electronic Temperatures in Recombining Nozzle Flow of Ionized Nitrogen-Hydrogen Mixture: Part 2-Experiments. J. Plasma Physics, vol. 9, part 2, pp. 217-234, 1973.

31. Arnold, J. O.; Whiting, E. E.; and Lyle, G. C.: Line-by-line Calculation of Spectra from diatomic Molecules and Atoms Assuming a Voigt Line Profile. J. Quantitative Spectroscopy and Radiative Transfer, vol. 9, pp. 775-798,1969.

32. Massey, H. S. W.; and Burhop, E. H. S.: Electronic and Ionic Impact Phenomena, Oxford University Press, London, 1954.

33. Bates, D. R.: Atomic and Molccular Processes, Chapt. 7, Academic Press, London, 1962.

34. Wiese, W. L.; Smith, M. W.; and Glennon, B. M: Atomic Transition probabilities, vol. I. Hydrogen through Neon., NSRDS-NBS 4, National Bureau of Standards, 1966.

35. Bates, D. R.; Kingston, A. E.; and McWhictcr, R. W.: Proceeding of Royal Society, London, Series A267, 1962, p. 279.

36. Gryzinsky, M.: Classical theory of Atomic Collisions: Theory of Inclastic Collisions. Physical Revicw, vol. 138, no. 2A, pp. 336-358, April 1965.

37. Gryzinsky, M.: Physical Review, vol. 115, no. 2, p. 374, 1959.

38. Park, C.: Spectral Line Intensitics in a Nonequilibrium Nitrogen Plasma. J. Quantitative Spcctroscopy and Radiative Heat Transfer, vol. 8, no. 10, pp. 1633-1653, 1968.

39. Gilmore, F. R.; Baner, E.; and McGowan, J. W.: A Review of Atomic and Molecular Excitation Mechanisms in Nonequilibrium Gases up to 20,000 K. J. Quantitative Spectroscopy and Radiative Heat Transfer, vol. 9, no. 1, pp. 157-183, Jan. 1969. 
40. Slinker, S.; and Ali, A. W.: Electron Excitation and Ionization Rate Coefficients for $\mathrm{N}_{2}$, $\mathrm{O}_{2}$, NO, N and $\mathrm{O}$, Naval Research Laboratory, Washington, D. C., Memorandum Report 4756, Feb. 1982.

41. Whiting, E. E.: An Empirical Approximation to the Voigt Profile. J. Quantitative Spectroscopy and Radiative Heat Transfer, vol. 8, pp. 1379-1384, 1968.

42. Park, C.: Curve of Growth for Van der Waals Broadened Spectral Lines. J. Quantitative Spectroscopy and Radiative Heat Transfer, vol. 24, pp. 289-292, 1980.

43. Crandall, D. H.; Kauppila, W. E.; Phanef, R. A.; Taylor, P. O.; and Dunn, G. H.: Absolute Cross Sections for Electron-Impact Excitation of $\mathrm{N}_{2}^{+}$. Physical Review, Serics A, vol. 9, no. 6, pp. 2545-2551, June 1974.

44. Cartwright, D. C.; Trajmar, S.; Chutjian, A.; Williams, W.: Electron Impact Excitation of Electronic States of $\mathrm{N}_{2}$. Intcgral Cross Sections at Incident Energies from 10 to 50 ev. Physical Revicw, Scrics A, vol. 16, no. 3, pp. 1041-1051, June 1977.

45. Imani, M.; and Borst, W. L.: Electron Impact Excitation of the Gamma Bands of Nitric Oxide. J. Chemical Physics, vol. 63, no. 8, pp. 3602-3605, Oct. 1975.

46. Wakia, K.: Differential and Integral Cross Sections for Electron Impact Excitation of $\mathrm{O}_{2}$ : II. Optically Forbidden transitions from ground state. J. Physics, series B: Atomic and Molecular Physics, vol. 11, no. 22, pp. 3931-3938, Nov. 1978.

47. Park, C.; and Mences, G. P.: Odd Nitrogen Production by Metcoroids. J. Geophysical Research, vol. 83, no. 8, pp. 4029 4035, Aug. 1978.

48. Allen, R. A.: Air Radiation Tables: Spectral Distribution Functions for Molecular Band Systems, AVCO-Everett Rescarch Laboratory, Everett, Mass., Research Report 236, April 1966.

49. Bauschlicher, C. W., Jr.; Langhoff, S. R.; and Taylor, P. R.: Theoretical Study of the Dissociation Encrgy and the Red and Violet Band System of CN. Astrophysics J., vol. 332 , pp. $531-538,1988$.

50. Park, C.; Howe, J. T.; Jaffe, R. L.; and Candler, G. V.: Chemical Kinetic Problems of Future NASA Missions, AIAA Paper AIAA-91-0464.

51. Park, C.: Noncquilibrium Hypersonic Acrothermodynamics, Published by John Willy and Sons, Inc., 1990.

52. Park, C.; Howc, J. T.; Jaffe, R. L.; and Candler, G. V.: Chemical Kinetic Problems of Super-Escapc Velocity Mars Entries: A Revicw and Extension, To be published. 
53, Lotz, W.: Electron-Impact Ionization Cross-Section and Ionization Rate Coefficients for Atoms and Ions from hydrogen to Calcium. Zeitschrift fur Physik, vol. 216, pp. 214-247, Oct. 1968.

54. Levin, D. A,; Loda, R. T.; Candler, G. V.; and Park, C.: Theory of radiation from Low Velocity Heated Air, AIAA Paper 90-0133, Jan. 1990.

55. Gross, R.; and Cohen, N.: J. Chemical Physics, vol. 48, p. 2582, 1968.

56. Boitnott, C. A.; and Warder, R. C.,Jr.: Shock Tube Measurements of Rotational Relaxation in Hydrogen. The Physics of Fluids, vol. 14, no. 11, November 1971.

57. Lensch, G.; and Gronig, H.: Experimental Determination of Rotational Relaxation in Molecular Hydrogen and Deuterium. Proceeding of the Eleventh International Symposium on Shock Tubes and Waves, edited by B. Ahlborn, A. Hertzberg and D. Russcll, University of Washington Press, Seattle, 1977.

58. Millikan, R. C.; and White, D. R.: Systematics of Vibrational Relaxation. J. Chemical Physics, vol. 39, pp. 3209-3213, 1963.

59. Park, C.: Assessment of Two-Temperature Kinetic Model for Dissociating and WeaklyIonizing Nitrogen. J. Thermophysics and Heat Transfer, vol. 2, pp. 8-16, January 1988.

60. Park, C.: Estimates of Excitation Energy of Diatomic Molecules in Expanding Flows, AIAA Paper 92-0805, Jan, 1992.

61. Allen, R. A.; Keck, J. C.; and Camm, J. C.: Nonequilibrium Radiation from Shock Heated Nitrogen and a Determination of the Recombination rate, AVCO-Everett Research Laboratory Report 110, June 1961, also Physics of Fluids, vol. 5, pp. 284-291, 1962.

62. Faizullov, F. S.; Sobolev, N. N.; and Kudryavtsev, E. M.: Spectroscopic Investigation of the State of the Gas Bohind a Shock Wave. Optics and Spectroscopy, vol. 8, pp. $400-404,1960$.

63. Gaydon, A. G.; and Hurle, I. R.: Measurements of Times of Vibrational Relaxation and Dissociation Behind Shock Waves in $\mathrm{N}_{2}, \mathrm{O}_{2}, \mathrm{CO}, \mathrm{CO}_{2}$ and $\mathrm{H}_{2}$, Eighth Symposium (International) on Combustion, Pasadena, CA. Proceedings published by Williams and Wilkins, Baltimorc, Maryland, pp. 309--318, 1962.

64. Lee, Jong-Hun: Electron-Impact Vibrational Relaxation in High-Temperature Nitrogen, AIAA Paper 92-0807, Jan. 1992.

65. Huo, W. M.; McKoy, V.; Lima, M. A. P.; and Gibson, T, L.: Electron-Nitrogen Molecule Collisions in High-Temperature Nonequilibrium Air. Progress in Astronautics and 
Aeronautics: Thermophysical Aspects of Re-Entry Flows, vol. 103, Edited by Jim Moss and Carl D. Scott, AIAA, New York, pp. 152-196, 1986.

66. Park, C.: Assessment of Two-Temperature Kinetic Model for Ionizing Air. J. Thermophysics and Heat Transfer, vol. 3, no. 3, pp. 233-244, July 1989.

67. Park, C.: A Revicw of Reaction Rates in High Temperature Air, AIAA Paper 89-1740, 1989.

68. Whiting, E. E.; Arnold, J. O.; Page, W. A.; and Reynolds, R. M.: Composition of the Earth's Atmosphere by Shock-Layer radiometry During PAET Entry probe Experimcnt. J. Quantitative Spectroscopy and Radiative Heat Transfer, vol. 9, pp. 837-859, 1973.

69. Whiting, E. E.; and Park, C.: Radiative Heating at the Stagnation Point of the AFE Vehicle, NASA TM-102829, November 1990.

70. Candler, G. V.; and MacCormack, R. W.: The Computation of Hypersonic ionized Flows in Chemical and Thermal Nonequilibrium, AIAA Paper 88-0511, January 1988.

71. Gnoffo, P. A.; Gupta, Roop, N.; and Shinn, J. L.: Conservation Equations and Physical Models for Hypersonic Air Flows in Thermal and Chemical Nonequilibrium, NASA TP-2867, February 1989.

72. Park, C. P.: Studics of Radiative Emission from the Simulated Shock Layer of the Huygens Probe, Ph. D. thesis, Department of Aeronautics and Astronautics, Stanford University, Stanford, CA, Dec. 1990.

73. Nelson, H. F.; Park, C.; and Whiting E. E.: Titan Atmospheric Composition by Hypervelocity Shock-Layer Analysis. J. Thermophysics and Heat Transfer, vol. 5, pp. 157-165, Nov. 2, April-June 1991.

74. Levin, D. A.; Candler, G. V.; Collins, R. J.; Erdman, R. W.; Zift, E.; Epsy, P.; and Howlett, C.: Comparison of Theory with experiment for the Bow Shock Ultraviolet Rocket Flight, AIAA Paper 91-1411, June 1991.

75. Candler, G. V.; Levin, D. A.; Collins, R. J.; Erdman, R. W.; Zift, E.; Epsy, P.; and Howlett, C.: Comparison of Theory with Plume Radiation Experiment for the Bow Shock Ultraviolet 2 Rocket Flight, AIAA Paper 92-0125, January 1992.

76. Wurster, W. H.; Treanor, C. E.; and Williams', M. J.: private communication.

77. Allen, R. A.: Noncquilibrium Shock Front Rotational, Vibrational and Electronic Temperature Mcasurcments, AVCO-Everett Research Laboratory Report 186, August 1964. 
78. Sharma, S. P.; and Whiting, E. E.: Modelling of Nonequilibrium Radiation phenomena: An Assessment, to be published.

79. Wilson, J. F.: Ionization Rate of Air Behind High-Speed Shock Waves. Physics of Fluids, vol. 9, pp. 1913-1921, 1966.

80. Sciff, A.; and Kirk, D. B.: Structure of the Atmosphere of Mars in Summer at MidAltitudes. J. Geographical Rescarch, vol. 62, no. 28, pp. 4364-4378, September 1977.

81. Camac, M.: $\mathrm{CO}_{2}$ Relaxation Processes in Shock Waves. Fundamental Phenomena in Hypersonic Flow, edited by J. G. Hall, Cornell University Press, Ithaca, NY, pp. 195-215, 1966.

82. Baulch, D. L.; Drysdale, D. D.; Duxbury, J.; and Grant, S. J.: Evaluated Kinetic Data for High Temperature Reactions, vol. 3, Homogeneous Gas phase Reactions of the $\mathrm{O}_{2}$ $\mathrm{O}_{3}$ system, the $\mathrm{CO}_{2}-\mathrm{O}_{2}-\mathrm{H}_{2}$ System, and of Sulphur-Containing Species, Butterworths, London, 1987.

83. Baulch, D. L.; Duxbury, J.; Grant, S. J.; and Montague, D. C.: Evaluated Kinetic Data for High Temperature Reactions, vol. 3, Homogeneous Gas phase Reactions of Halogenand Cynide-Containing Species. J. Physical and Chemical Reference Data, vol. 10, supplement no. 1, 1981.

84. Hindelang, F. J.: Coupled Vibration and Dissociation relaxation Behind Strong Shock Waves in Carbon Dioxide, NASA TR-R-253, February 1967.

85. McKenzie, R. L.: The Quantitative behaviour of Effects of Nonequilibrium Chemistry Behind Strong Shock Waves in Gas Mixtures of $\mathrm{CO}_{2}$ and $\mathrm{N}_{2}$. Proceedings of the AIAA/AAS Stepping Stones to Mars Meeting, Baltimore, MD, pp. 391-409, March 1966.

86. Thomas, G. M.; and Menard, W. A.: Experimental Measurements of Nonequilibrium and Equilibrium Radiation from Planetary Atmospheres. AIAA J., vol. 4, no. 2, pp. 227-237, February 1966.

87. Arnold, J. O.; and Nicholls, R. W.: A Shock-Tube Determination of the CN Ground State Dissociation Energy and Electronic Transition Moments for the CN Violet and Red Band Systems. Recent Development in Shock Tube rescarch: proceedings of the 9th International Symposium on Shock Tubes and Waves, edited by D. Bershader and W. Griffith, Stanford University Press, Stanford, CA, pp. 340-351, 1973.

88. Davics, W. O.: Carbon Dioxide Dissociation at 6000 to 11000 K. J. Chemical Physics, vol. 43, no. 8, pp. 2809 2815, October 1965. 
89. Nealy, J. E.; and Haggard, K. V.: A Shock Tube Study of Radiation Behind Shock Waves in $\mathrm{CO}_{2}$ with Applications to Venus Entry, Proceedings of the 9th International Symposium on Shock Tubes and Waves, edited by D. Bershader and W. Griffith, Stanford University Press, Stanford, CA, pp. 330-339, 1973.

90. Howe, J. T.: Viegas, J. R.; and Sheaffer, Y. S.: Study of Nonequilibrium Flow Field Behind Normal Shock Waves in Carbon Dioxide, NASA TN D-1885, June 1963.

91. Freeman, G. N.; and Oliver, C. C.: Chemical Nonequilibrium Viscous Radiating Blunt Body Shock Layers in $\mathrm{CO}_{2}-\mathrm{N}_{2}$ Atmospheres, AIAA Paper 71-35, January 1971.

92. Candler, G. V.: Computation of Thermochemical Nonequilibrium Martian Atmospheric Entry Flows, AIAA Paper 90-1695, June 1990.

93. Hunten, D. M.; Tomasko, M. G.; Flasar, F. M.; Samuelson, R. E.; Strobel, D. F.; and Stevenson, D. J.: Titan. Saturn, edited by T. Gehrels and M. S. Matthews, University of Arizona Press, Tucson, AZ, pp. 671-759, 1984. 
Table 1. Reaction rate coefficients for air; $T_{x}$ is the controlling temperature, $C$ is in $\mathrm{cm}^{3} \mathrm{~mole}^{-1} \mathrm{~s}^{-1}$

\begin{tabular}{|c|c|c|c|c|c|c|}
\hline & $\mathbf{M}$ & $\mathrm{T}_{x}$ & $\mathrm{C}$ & $n$ & $\mathrm{~T}_{d}$ & $\begin{array}{l}\text { Experimental data } \\
\text { available? }\end{array}$ \\
\hline \multicolumn{7}{|l|}{ Dissociation Reactions } \\
\hline $\mathrm{N}_{2}+\mathrm{M} \rightarrow \mathrm{N}+\mathrm{N}+\mathrm{M}$ & $\begin{array}{l}\mathrm{N} \\
\mathrm{O} \\
\mathrm{N}_{2} \\
\mathrm{O}_{2} \\
\mathrm{NO} \\
\mathrm{N}^{+} \\
\mathrm{O}^{+} \\
\mathrm{N}_{2}^{+} \\
\mathrm{O}_{2}^{+} \\
\mathrm{NO}^{+} \\
\mathrm{e}^{-}\end{array}$ & $T_{a}$ & $\begin{array}{l}3.0^{22} \\
3.0^{22} \\
7.0^{21} \\
7.0^{21} \\
7.0^{21} \\
3.0^{22} \\
3.0^{22} \\
7.0^{21} \\
7.0^{21} \\
7.0^{21} \\
1.2^{25}\end{array}$ & -1.60 & 113200 & $\begin{array}{l}\text { yes } \\
\text { no } \\
\text { yes } \\
\text { no } \\
\text { no } \\
\text { no } \\
\text { no } \\
\text { no } \\
\text { no } \\
\text { no } \\
\text { no }\end{array}$ \\
\hline $\mathrm{O}_{2}+\mathrm{M} \rightarrow \mathrm{O}+\mathrm{O}+\mathrm{M}$ & $\begin{array}{l}\mathrm{N} \\
\mathrm{O} \\
\mathrm{N}_{3} \\
\mathrm{O}_{2} \\
\mathrm{NO} \\
\mathrm{N}^{+} \\
\mathrm{O}^{+} \\
\mathrm{N}_{2}^{+} \\
\mathrm{O}_{2}^{+} \\
\mathrm{NO}^{+} \\
\end{array}$ & $\mathrm{T}_{a}$ & $\begin{array}{l}1.0^{22} \\
1.0^{22} \\
2.0^{21} \\
2.0^{21} \\
2.0^{21} \\
1.0^{22} \\
1.0^{22} \\
2.0^{21} \\
2.0^{21} \\
2.0^{21} \\
\end{array}$ & -1.50 & 59500 & $\begin{array}{l}\text { no } \\
\text { yes } \\
\text { yes } \\
\text { yes } \\
\text { no } \\
\text { no } \\
\text { no } \\
\text { no } \\
\text { no } \\
\text { no } \\
\end{array}$ \\
\hline $\mathrm{NO}+\mathrm{M} \rightarrow \mathrm{O}+\mathrm{O}+\mathrm{M}$ & $\begin{array}{l}\mathrm{N} \\
\mathrm{O} \\
\mathrm{N}_{2} \\
\mathrm{O}_{2} \\
\mathrm{NO} \\
\mathrm{N}^{+} \\
\mathrm{O}^{+} \\
\mathrm{N}_{2}^{+} \\
\mathrm{O}_{2}^{+} \\
\mathrm{NO}^{+}\end{array}$ & $T_{a}$ & $\begin{array}{l}1.1^{17} \\
1.1^{17} \\
5.0^{15} \\
5.0^{15} \\
1.1^{17} \\
1.1^{17} \\
1.1^{17} \\
5.0^{15} \\
5.0^{15} \\
5.0^{15} \\
\end{array}$ & 0.00 & 75500 & $\begin{array}{l}\text { no } \\
\text { no } \\
\text { no } \\
\text { no } \\
\text { yes } \\
\text { no } \\
\text { no } \\
\text { no } \\
\text { no } \\
\text { no } \\
\end{array}$ \\
\hline NO Exchange Reactions & & . & & & & \\
\hline $\begin{array}{l}\mathrm{NO}+\mathrm{O} \rightarrow \mathrm{N}+\mathrm{O}_{2} \\
\mathrm{~N}_{2}+\mathrm{O} \rightarrow \mathrm{NO}+\mathrm{N}\end{array}$ & & $\begin{array}{l}\mathrm{T} \\
\mathrm{T}\end{array}$ & $\begin{array}{l}8.4^{12} \\
6.4^{17} \\
\end{array}$ & $\begin{array}{c}0.00 \\
-1.00 \\
\end{array}$ & $\begin{array}{l}19450 \\
38400 \\
\end{array}$ & $\begin{array}{l}\text { yes } \\
\text { yes }\end{array}$ \\
\hline \multicolumn{7}{|c|}{ Associative Ionization Reactions } \\
\hline $\begin{array}{l}\mathrm{N}+\mathrm{O} \rightarrow \mathrm{NO}^{+}+\mathrm{e}^{-} \\
\mathrm{O}+\mathrm{O} \rightarrow \mathrm{O}_{2}^{+}+\mathrm{e}^{-} \\
\mathrm{N}+\mathrm{N} \rightarrow \mathrm{N}_{2}^{+}+\mathrm{e}^{-}\end{array}$ & & $\begin{array}{l}T \\
T \\
T\end{array}$ & $\begin{array}{l}8.8^{8} \\
7.1^{2} \\
4.4^{7}\end{array}$ & $\begin{array}{l}1.00 \\
2.70 \\
1.50\end{array}$ & $\begin{array}{l}31900 \\
80600 \\
67500\end{array}$ & $\begin{array}{l}\text { yes } \\
\text { yes } \\
\text { yes }\end{array}$ \\
\hline \multicolumn{7}{|l|}{ Charge Exchange Reactions } \\
\hline $\begin{array}{l}\mathrm{NO}^{+}+\mathrm{O} \rightarrow \mathrm{N}^{+}+\mathrm{O}_{2} \\
\mathrm{~N}^{+}+\mathrm{N}_{2} \rightarrow \mathrm{N}_{2}^{+}+\mathrm{N} \\
\mathrm{O}_{2}^{+}+\mathrm{N} \rightarrow \mathrm{N}^{+}+\mathrm{O}_{2} \\
\mathrm{O}^{+}+\mathrm{NO} \rightarrow \mathrm{N}^{+}+\mathrm{O}_{2} \\
\mathrm{O}_{2}^{+}+\mathrm{N}_{2} \rightarrow \mathrm{N}_{2}^{+}+\mathrm{O}_{2} \\
\mathrm{O}_{2}^{+}+\mathrm{O} \rightarrow \mathrm{O}^{+}+\mathrm{O}_{2} \\
\mathrm{NO}^{+}+\mathrm{N} \rightarrow \mathrm{O}^{+}+\mathrm{N}_{2} \\
\mathrm{NO}^{+}+\mathrm{O}_{2} \rightarrow \mathrm{O}_{2}^{+}+\mathrm{NO} \\
\mathrm{NO}^{+}+\mathrm{O} \rightarrow \mathrm{O}_{2}^{+}+\mathrm{N} \\
\mathrm{O}^{+}+\mathrm{N}_{2} \rightarrow \mathrm{N}_{2}^{+}+\mathrm{O} \\
\mathrm{NO}^{+}+\mathrm{N} \rightarrow \mathrm{N}_{2}^{+}+\mathrm{O}\end{array}$ & . & $\begin{array}{l}\mathrm{T} \\
\mathrm{T} \\
\mathrm{T} \\
\mathrm{T} \\
\mathrm{T} \\
\mathrm{T} \\
\mathrm{T} \\
\mathrm{T} \\
\mathrm{T} \\
\mathrm{T} \\
\mathrm{T}\end{array}$ & $\begin{array}{l}1.0^{12} \\
1.0^{12} \\
8.7^{13} \\
1.4^{5} \\
9.9^{12} \\
4.0^{12} \\
3.4^{13} \\
2.4^{13} \\
7.2^{12} \\
9.1^{11} \\
7.2^{13}\end{array}$ & $\begin{array}{l}0.50 \\
0.50 \\
0.7 \\
1.90 \\
0.00 \\
-0.09 \\
-1.08 \\
0.41 \\
0.29 \\
0.36 \\
0.00 \\
\end{array}$ & $\begin{array}{l}77200 \\
12200 \\
28600 \\
26600 \\
40700 \\
18000 \\
12800 \\
32600 \\
48600 \\
22800 \\
35500 \\
\end{array}$ & $\begin{array}{l}\text { yes } \\
\text { no } \\
\text { yes } \\
\text { yes } \\
\text { yes } \\
\text { yes } \\
\text { yes } \\
\text { yes } \\
\text { yes } \\
\text { yes } \\
\text { yes }\end{array}$ \\
\hline
\end{tabular}




\begin{tabular}{|c|c|c|c|c|c|}
\hline & $\mathrm{T}_{x}$ & $\mathrm{C}$ & $n$ & $\mathrm{~T}_{d}$ & $\begin{array}{l}\text { Experimental data } \\
\text { available? }\end{array}$ \\
\hline \multicolumn{6}{|c|}{ Electron-Impact Ionization Reactions } \\
\hline $\begin{array}{l}\mathrm{O}+\mathrm{e}^{-} \rightarrow \mathrm{O}^{+}+\mathrm{e}^{-}+\mathrm{e}^{-} \\
\mathrm{N}+\mathrm{e}^{-} \rightarrow \mathrm{N}^{+}+\mathrm{e}^{-}+\mathrm{e}^{-}\end{array}$ & $\begin{array}{l}\mathrm{T}_{e} \\
\mathrm{~T}_{e}\end{array}$ & $\begin{array}{l}3.9^{33} \\
2.5^{34} \\
\end{array}$ & $\begin{array}{l}-3.78 \\
-3.82 \\
\end{array}$ & $\begin{array}{l}158500 \\
168600 \\
\end{array}$ & $\begin{array}{l}\text { no } \\
\text { yes }\end{array}$ \\
\hline \multicolumn{6}{|c|}{ Radiative Recombination Reactions } \\
\hline $\begin{array}{l}\mathrm{O}^{+}+\mathrm{e}^{-} \rightarrow \mathrm{O}+\mathrm{h} \nu \\
\mathrm{N}^{+}+\mathrm{e}^{-} \rightarrow \mathrm{N}+\mathrm{h} \nu\end{array}$ & $\begin{array}{l}\mathrm{T}_{e} \\
\mathrm{~T}_{e}\end{array}$ & $\begin{array}{l}1.07^{11} \\
1.52^{11}\end{array}$ & $\begin{array}{r}-0.52 \\
-0.48\end{array}$ & & $\begin{array}{l}\text { no } \\
\text { no }\end{array}$ \\
\hline
\end{tabular}
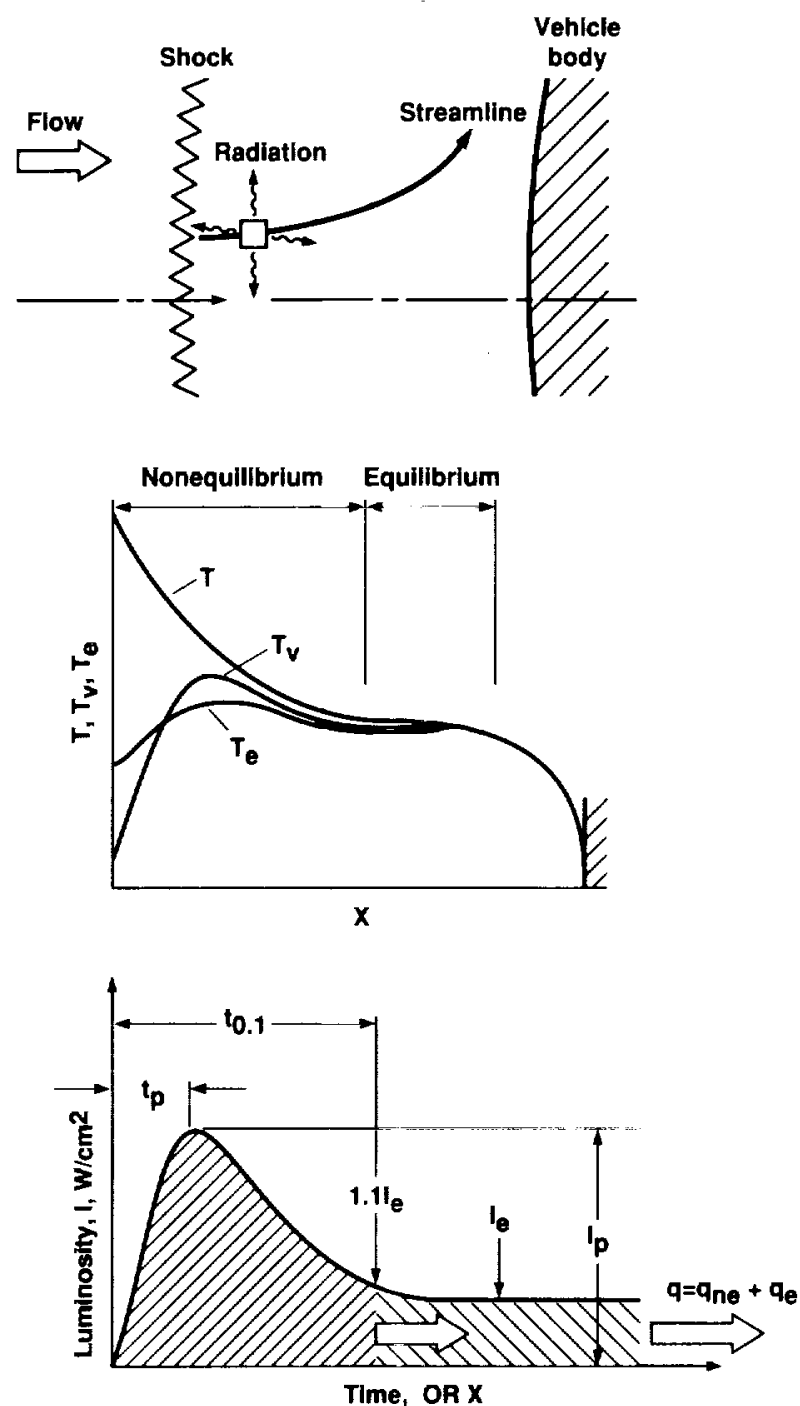

Figure 1. Concepts of nonequilibrium radiation: 1) shock layer, 2) approximate temperature profiles, and 3) nonequilibrium radiation characteristics. 


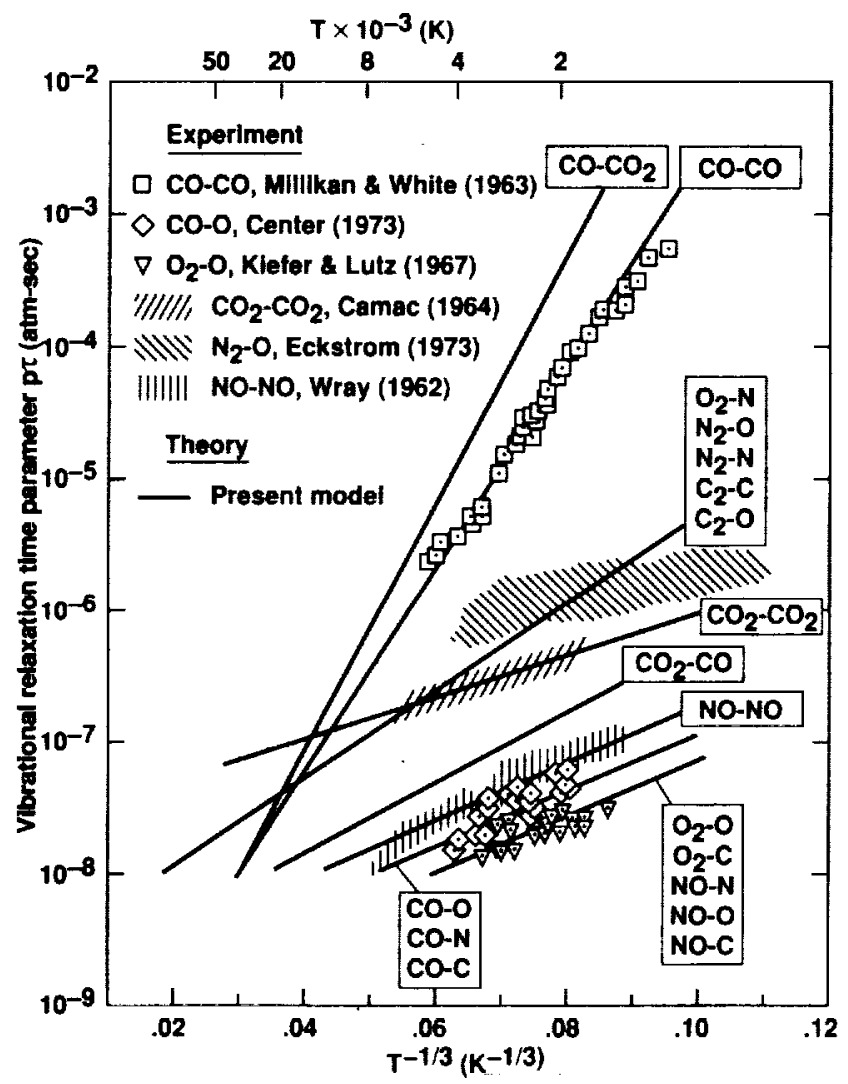

Figure 2. Vibrational relaxation times as functions of temperature. 

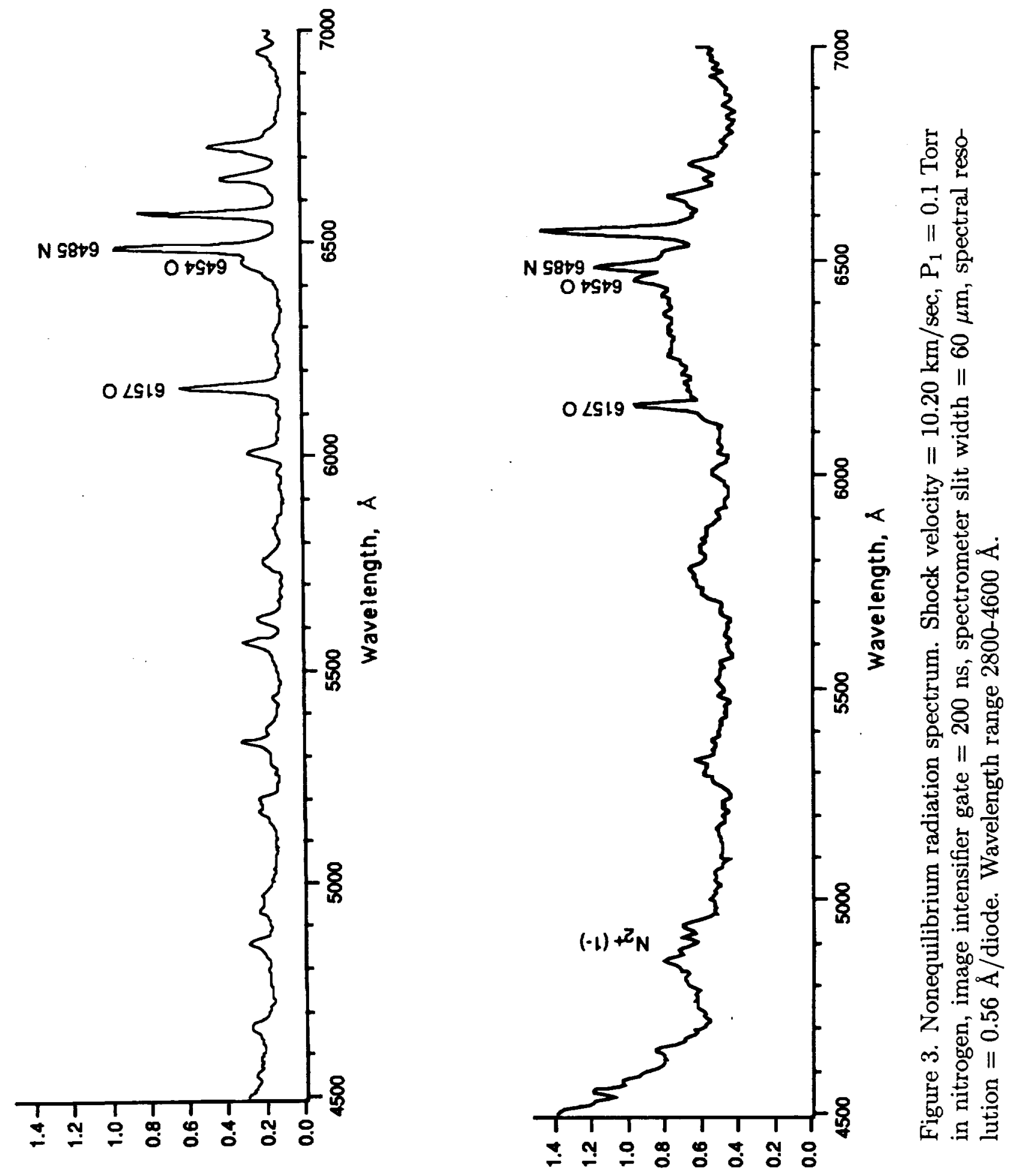

Js $w r{ }_{\varepsilon} w \partial / M$ 'AqIsuazul әznlosqy

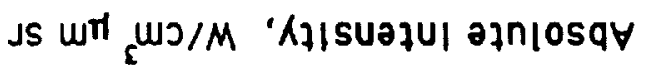




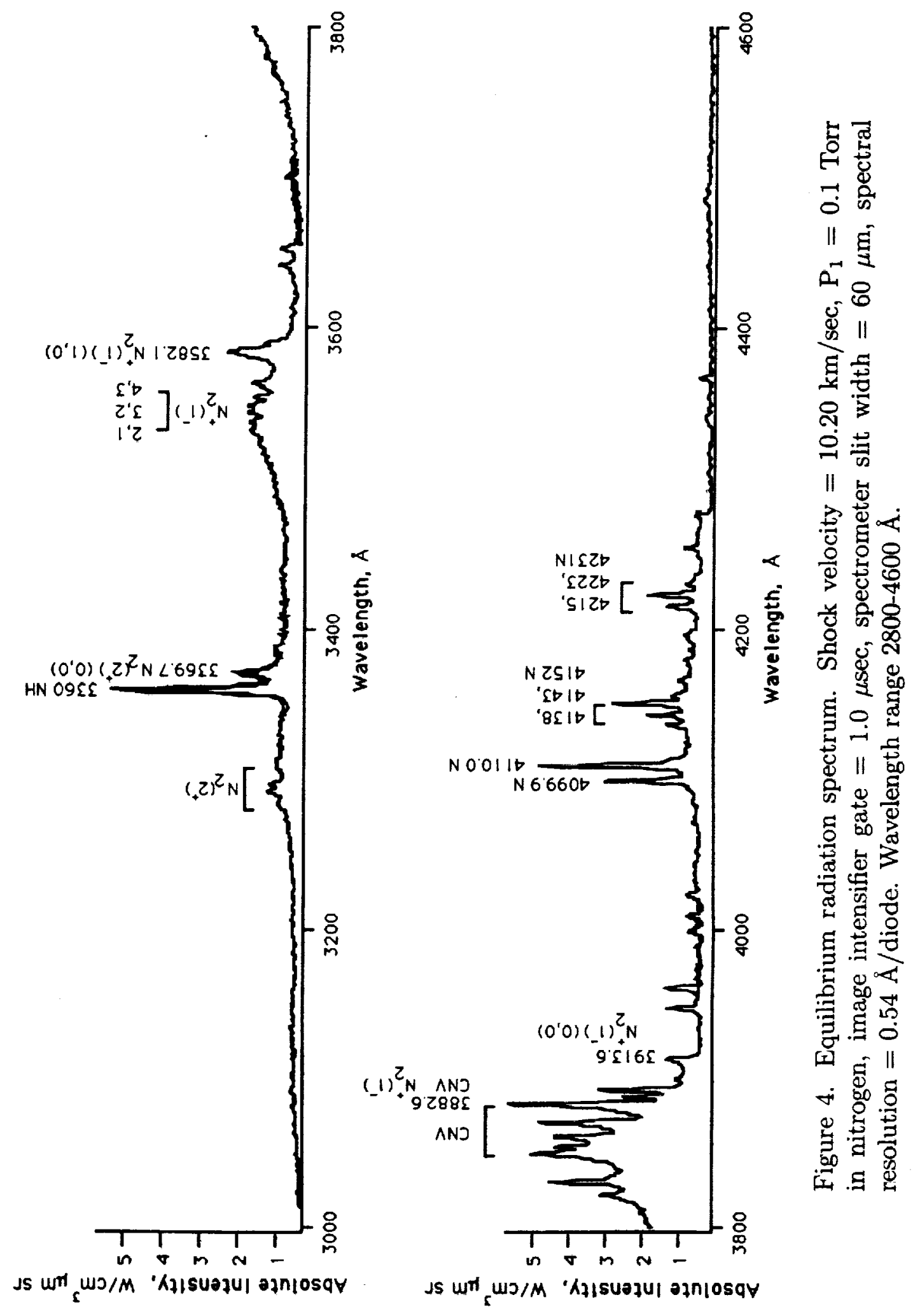




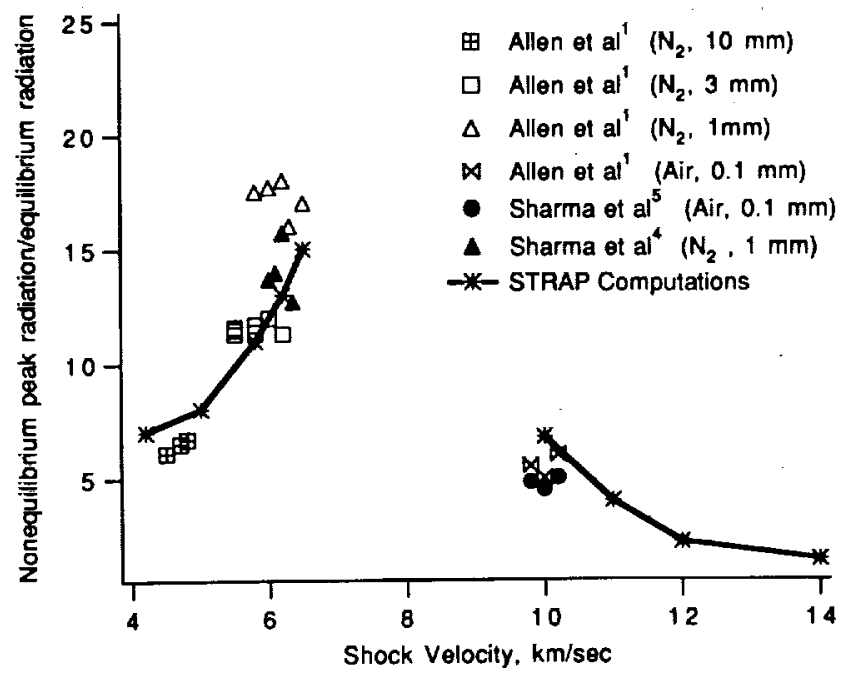

Figure 5. Ratio of peak nonequilibrium radiation to the equilibrium radiation as recorded in various shock tube experiments.

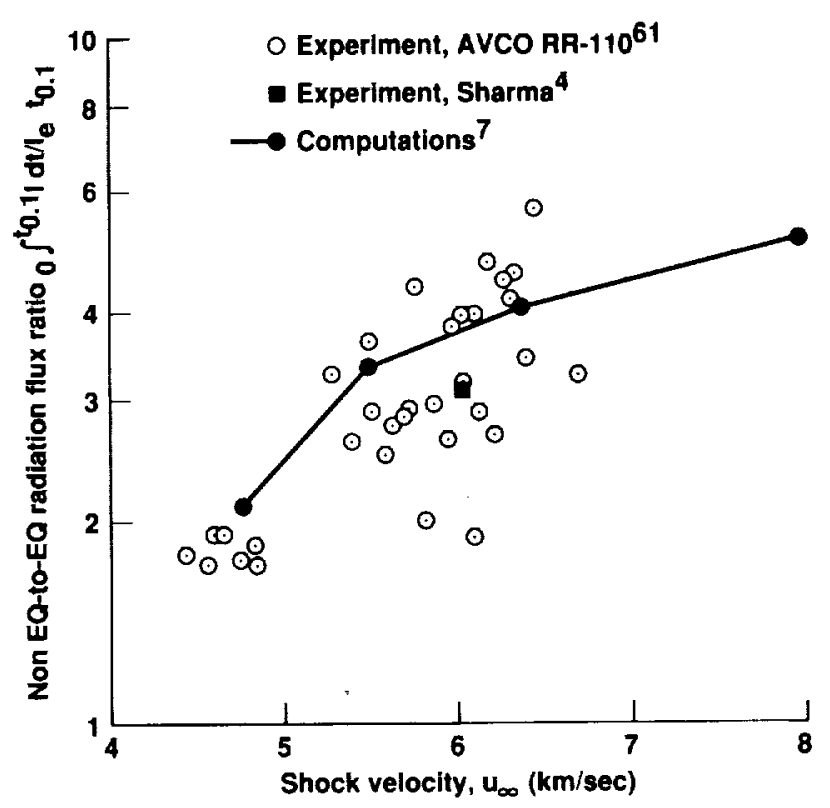

Figure 6. Nonequilibrium-to-equilibrium radiation heat-flux ratio as function of shock velocity. 


\section{COMPARISON BETWEEN CALCULATED AND MEASURED \\ SPECTRA AT PEAK-RADIATION POINT \\ $P_{\infty}=0.1$ torr, $V_{\infty}=10 \mathrm{~km} / \mathrm{sec}$}

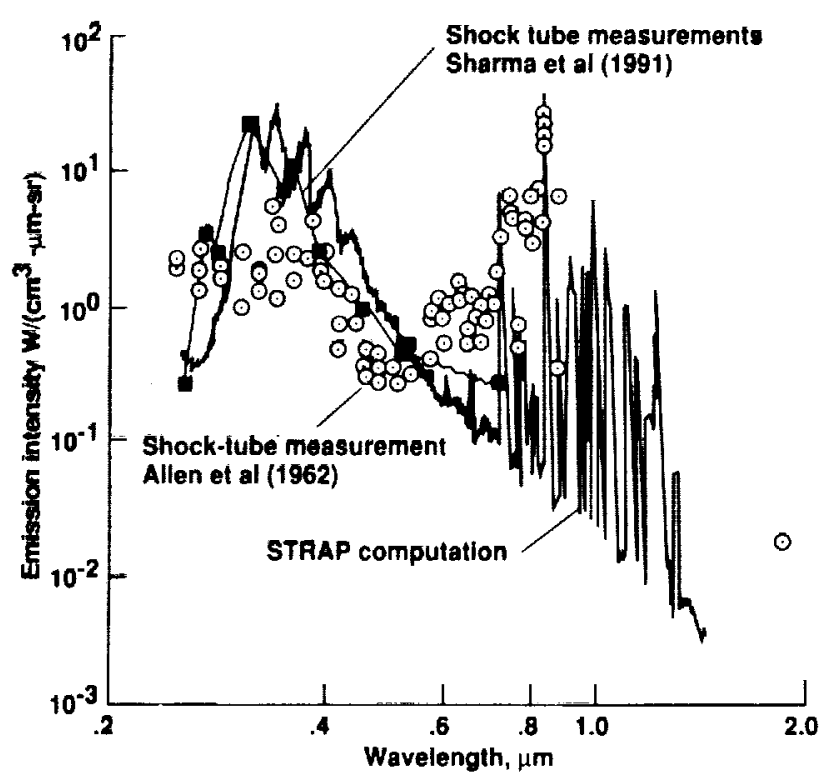

Figure 7. Nonequilibrium spectral emission data compared with the synthetic spectrum.

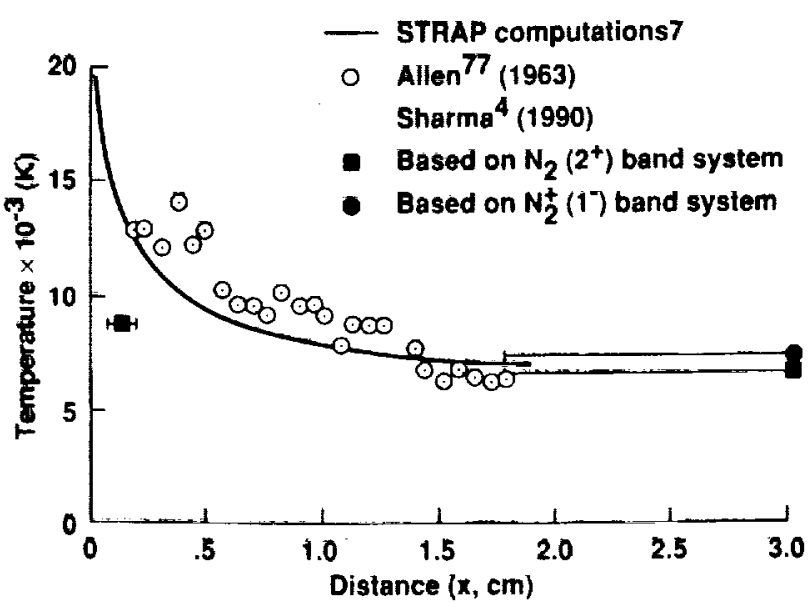

Figure 8. The measured rotational temperature compared with the AVCO data (ref. 77) and with the theoretical values computed by Park (ref. 59) using a) average temperature, b) vibrational temperature, and c) translational temperature. 


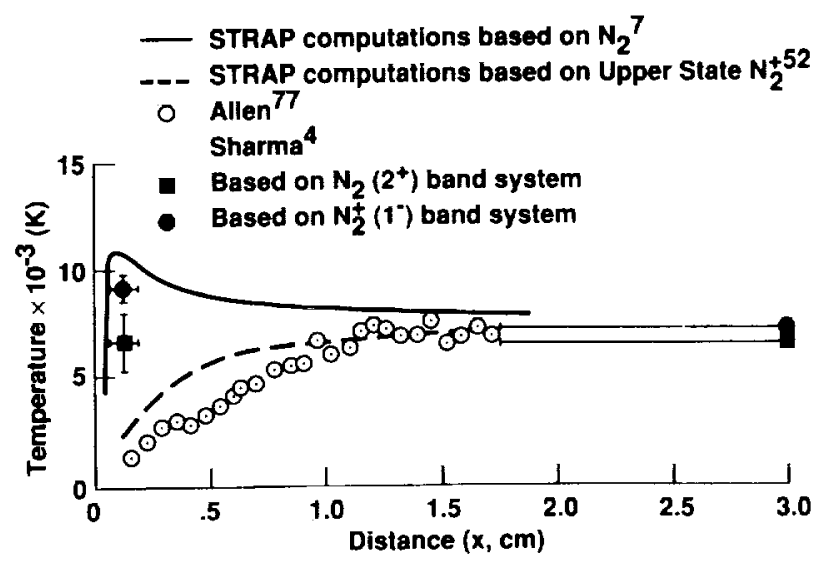

Figure 9. The measured vibrational temperature compared with the AVCO data (ref. 77) and with the theoretical values computed by Park (ref. 59) using a) average temperature, b) vibrational temperature, and c) translational temperature.

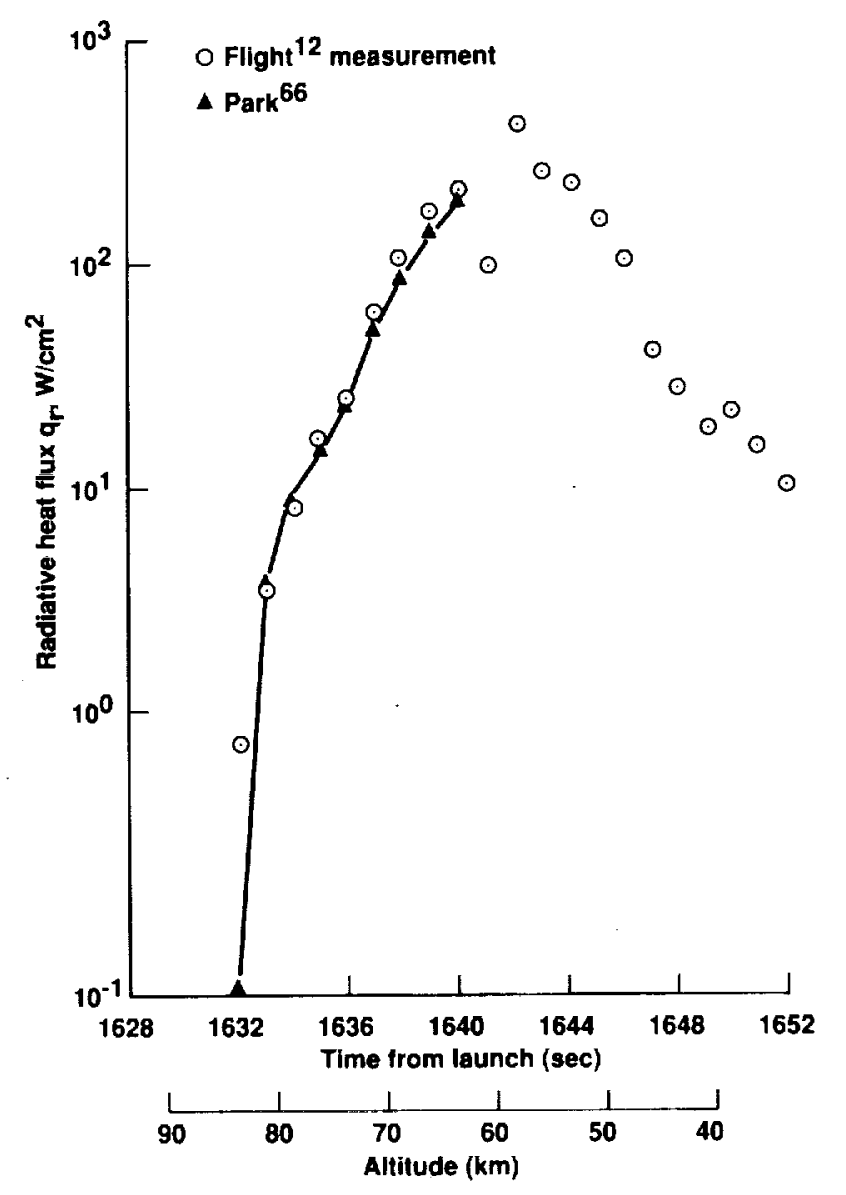

Figure 10. Comparison between calculated and measured stagnation-point radiative heat fluxes for FIRE 2 (ref. 66). 


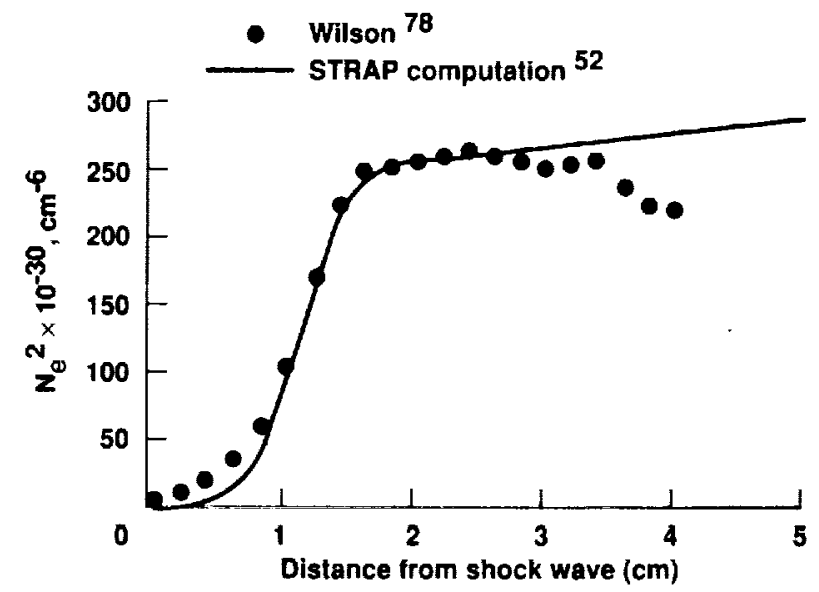

Figure 11. Comparison between Wilson's experimental data and the data predicted by STRAP.

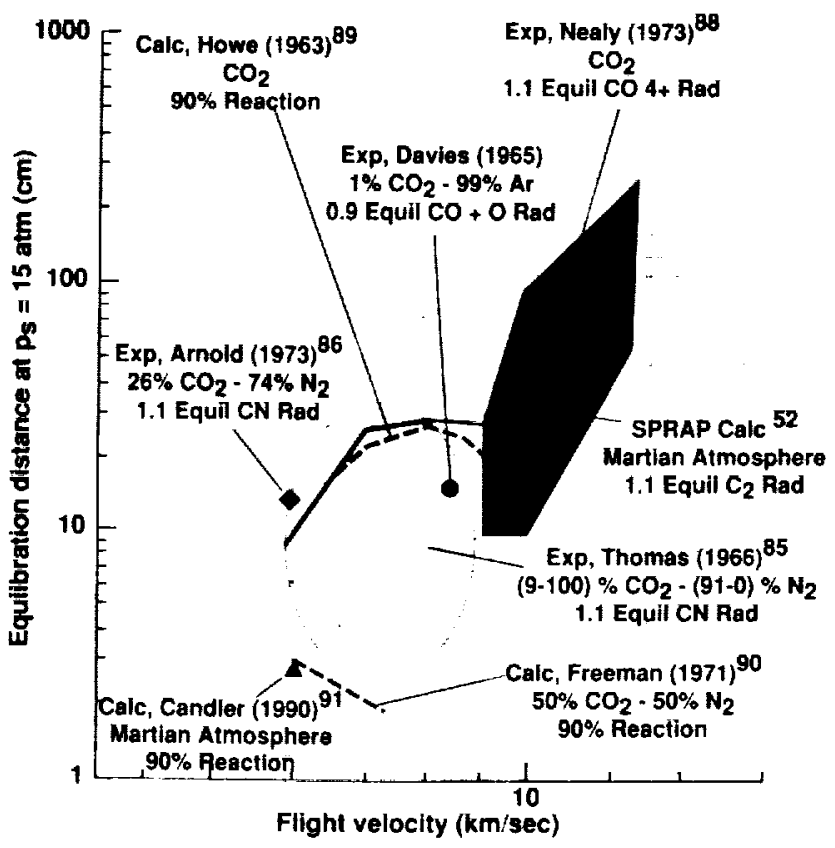

Figure 12. Comparison between the cquilibrium distance at post shock pressure of $0.15 \mathrm{~atm}$ in Martian atmosphere predicted by the present model and the existing experimental data (refs. 85-88) and other theoretical predictions (refs. 89-91). 

Public reporting burden for this collection of intormation is entimaled to ever age 1 hour per response, including the time for roviewing ingtructions, searching exiating deta sources, gathering and maintahing the deta needed, and completing and reviowing the coltection of information. Send commenta regarding this burden ertimate or any other aspect of this Devis Highway, Sulte 1204, Aslington, VA 22202-4302, and to the Otfice of Management end Budget, Papenwork Reduction Project (0704-0188). Weahington, DC 20s03.
1. AGENCY USE ONLY (Leave blenk)
2. REPORT DATE
January 1993
3. AEPORT TYPE AND DATES COVEAED
Technical Memorandum

4. TITLE AND SUBTITLE

Assessment of Nonequilibrium Radiation Computation Methods for Hypersonic Flows

6. AUTHOR(S)

$506-40$

Surendra Sharma

7. PERFoRMING ORGANIZATION NAME(S) AND ADDRESS(ES)

Ames Research Center

Moffett Field, CA 94035-1000

A-93023

9. SPONSORING/MONITORING AGENCY NAME(S) AND ADDRESS(ES)

10. SPONSORING/MONITOAING AGENCY REPORT NUMBER

National Aeronautics and Space Administration

Washington, DC 20546-0001

NASA TM-103994

11. SUPPLEMENTAAY NOTES

Point of Contact: Surendra Sharma, Ames Research Center, MS 230-2, Moffett Field, CA 94035-1000, (415) 604-3432

12a. DISTRIBUTION/AVALLABILITY STATEMENT

12b. DISTRIBUTtION CODE

Unclassified-Unlimited

Subject Category - 34

13. ABSTRACT (MaXimum 200 words)

The present understanding of shock-layer radiation in the low density regime, as appropriate to hypersonic vehicles, is surveyed. Based on the relative importance of electron excitation and radiation transport, the hypersonic flows are divided into three groups: weakly ionized, moderately ionized, and highly ionized flows. In the light of this division, the existing laboratory and flight data are scrutinized. Finally, an assessment of the nonequilibrium radiation computation methods for the three regimes in hypersonic flows is presented. The assessment is conducted by comparing experimental data against the values predicted by the physical model.

14. SUBJECT TERMS

Nonequilibrium radiation, Hypersonic flows, Radiative heat transfer

15. NUMBER OF PAGES

42

16. PAICE CODE

$\mathrm{A} 03$

\begin{tabular}{|c|c|c|c|}
\hline $\begin{array}{l}\text { 17. SECUAITY CLASSIFICATION } \\
\text { OF REPOAT } \\
\text { Unclassified }\end{array}$ & $\begin{array}{l}\text { 18. SECURITY CLASSIFICATION } \\
\text { OF THIS PAGE } \\
\text { Unclassified }\end{array}$ & $\begin{array}{l}\text { 19. SECUAITY CLASSIFICATION } \\
\text { OF ABSTRACT }\end{array}$ & 20. LIMITATION OF ABSTRACT \\
\hline
\end{tabular}

